RODRIGO CANTAMESSA GONÇALVES

\title{
ESTRATÉGIAS TERAPÊUTICAS PARA INIBIR 0 CRESCIMENTO DE BIOFILME PRODUZIDO POR CEPAS MULTIRRESISTENTES DE PSEUDOMONAS AERUGINOSA REPRESENTATIVAS DE CLONES E/OU GENÓTIPOS DE RESISTÊNCIA ENDÊMICOS NO BRASIL
}

Dissertação apresentada ao Programa de Pós-Graduação em Microbiologia do Instituto de Ciências Biomédicas da Universidade de São Paulo, para obtenção do título de Mestre em Ciências. 
RODRIGO CANTAMESSA GONÇALVES

Estratégias terapêuticas para inibir o crescimento de biofilme produzido por cepas multirresistentes de Pseudomonas aeruginosa representativas de clones e/ou genótipos de resistência endêmicos no Brasil

Dissertação apresentada ao Programa de Pós-Graduação em Microbiologia do Instituto de Ciências Biomédicas da Universidade de São Paulo, para obtenção do título de Mestre em Ciências.

Área de Concentração: Microbiologia

Orientador: Prof. Dr. Nilton Erbet Lincopan Huenuman

Versão original 
DADOS DE CATALOGAÇÅO NA PUBLICAÇÅO (CIP)

Serviço de Biblioteca e Informação Biomédica do

Instituto de Cièncias Biomédicas da Universidade de São Paulo

reproduçăo năo autorizada pelo autor

\section{Gonçalves, Rodrigo Cantamessa.}

Estratégias terapêuticas para inibir o crescimento de biofilme produzido por cepas multirresistentes de Pseudomonas aeruginosa representativas de clones e/ou genótipos de resistência endèmicos no Brasil / Rodrigo Cantamessa Gonçalves. - São Paulo, 2014.

Orientador. Prof. Dr. Nilton Erbet Lincopan Huenuman.

Dissertaçäo (Mestrado) - Universidade de Säo Paulo. Instituto de Ciências Biomédicas. Departamento de Microbiologia. Área de concentraçäo: Microbiologia. Linha de pesquisa: Resistência bacteriana e alternativas terapeuticas.

Versäo do título para o inglês: Therapeutic strategies to inhibit the growth of biofilms produced by strains of multiresistant Pseudomonas aeruginosa representative of clones and/or exhibiting resistance genotypes endemic in Brazil.

1. Biofilme 2. Fagoterapia 3. Multirresistência 4. Sinergismo I. Lincopan, Prof. Dr. Nilton Erbet Huenuman II. Universidade de Säo Paulo. Instituto de Cièncias Biomédicas. Programa de Pós-Graduaçäo em Microbiologia III. Título. 
UNIVERSIDADE DE SÃO PAULO

INSTITUTO DE CIÉNCIAS BIOMÉDICAS

Candidato(a):

Título da Dissertação:

Orientador(a):
Rodrigo Cantamessa Gonçalves.

Estratégias terapêuticas para inibir o crescimento de biofilme produzido por cepas multirresistentes de Pseudomonas aeruginosa representativas de clones e/ou genótipos de resistência endêmicos no Brasil.

Prof. Dr. Nilton Erbet Lincopan Huenuman.

\section{A Comissão Julgadora dos trabalhos de Defesa da Dissertação de Mestrado, em sessão pública realizada a I.. I................., considerou \\ ( ) Aprovado(a) ( ) Reprovado(a)}

$\begin{array}{ll}\text { Examinador(a): } & \begin{array}{l}\text { Assinatura: } \\ \text { Nome: } \\ \text { Instituição: }\end{array} \\ \text { Examinador(a): } & \begin{array}{l}\text { Assinatura: } \\ \text { Nome: } \\ \text { Instituição: }\end{array} \\ \text { Presidente: } & \begin{array}{l}\text { Assinatura: } \\ \text { Nome: } \\ \text { Instituição: }\end{array}\end{array}$ 
Cidade Universitária "Armando de Salles Oliveira"

Av. Prof. Lineu Prestes, 2415 - CEP. 05508-000 São Paulo, SP - Bras

Telefone :(55) (11) 3091-7733 - telefax : (55) (11) 3091-8405

e-mail: cep@icb.usp.br

Comissão de Ética em Pesquisa

\title{
CERTIFICADO DE ISENÇÃO
}

\author{
Certificamos que o Protocolo CEP-ICB N $\mathrm{N}^{\circ}$ 534/12
}

referente ao projeto intitulado: "Avaliação da atividade bacteriana de bacteriófagos líticos sobre modelo de biofilme de Pseudomonas aeruginosa multirresistente produtora de metalo-beta-lactamase" sob a responsabilidade de Rodrigo Cantamessa Gonçalves, foi analisado na presente data pela CEUA - COMISSÃo DE ÉTICA NO USO DE ANIMAIS e pela CEPSHComissão de Ética em Pesquisa com seres humanos, tendo sido deliberado que o referido projeto não utilizará animais que estejam sob a égide da lei 11.794 de 8 de outubro de 2008, nem envolverá procedimentos regulados pela Resolução CONEP nº196 de 1996.

São Paulo, 18 de setembro de 2012.

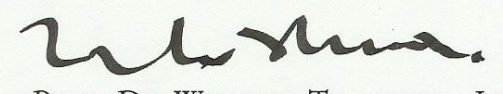

PROF. DR. WOTHAN TAVARES DE LIMA Coordenador da CEUA - ICB/USP

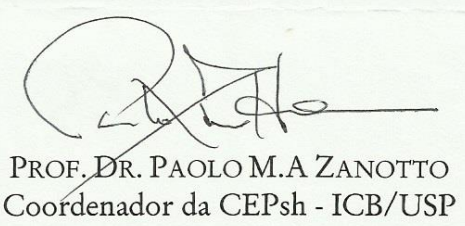


Dedico este trabalho aos mens pais, que tanto me apoiaram para que pudesse me tornar o profissional que sow.

Dedico aos meus irmãos, tanto of de sangue quanto os que ew encontrei ao longo da vida, pois deles vem a força que me move.

Dedico aos amigos que estão sempre em minha mesa. Sempre estarei aqui para hutar contra e ao lado de vocês.

Dedico este trabalho a minha esposa Talita. Você é minha Súmaril, luz que me guia nos momentos ruins e que me aquece nos bons. 


\section{AGRADECIMENTOS}

Agradeço a minha mãe Márcia, pelo cuidado e apoio que sempre me ofereceu, pelo exemplo de perseverança e trabalho duro e pelo amor e carinho que sempre recebi.

Ao meu pai Silvio, que me estimulou a sempre buscar mais e focar na minha educação.

Aos meus irmãos Fernando, Milena e Matheus, que tanto agitam e alegram minha vida.

Agradeço a minha esposa Talita, maior companheira que eu poderia pedir. Eu me apaixonei quando te vi na bio e te amei quando passou a proteger os Reinos a meu lado. É por nós que este mestrado foi concluído.

A meus avós, Durival, Meire e Dedé, por todo o carinho e apoio.

Agradeço aos meus amigos que me acompanham desde a infância ou surgiram na faculdade. É com grande pesar que os vejo tão pouco, mas isso não significa que não estejam sempre em meus pensamentos.

Ao grupo que me acompanhou em tantas tardes chuvosas, cavalgando por Faerûn e tantos outros mundos. Combater ao vosso lado é uma honra.

Agradeço as minhas amigas Tatiane e Luana, maior presente que recebi durante este mestrado. Sem o apoio e a amizade de vocês, este projeto jamais teria visto seu fim.

Ao meu orientador Prof. Dr. Nilton Lincopan, por me ensinar muito mais do que imagina.

Agradeço a Lucianne, Patrícia, Helena, Juan, Micheli, Ednei, Quézia, Lívia, Priscila, Lúcia e Jacinta pelo convívio e auxílio diário no laboratório.

Agradeço a CAPES e ao Departamento de Microbiologia do Instituto de Ciências Biomédicas da USP, pelo financiamento deste projeto e por oferecer os recursos necessários para sua realização.

Agradeço a Gisele, por me ajudar a superar as burocracias da pós-graduação. 
"É mais importante Ser do que Ter. Qualquer um pode perder suas posses, mas ninguém pode lhe tirar aquilo que você é."

"It's a dangerous business, Frodo, going out your door. You step onto the road, and if you don't keep your feet, there's no knowing where you might be swept off to." - J.R.R. Tolkien, The Lord of the Rings 


\section{RESUMO}

CANTAMESSA, R. G. Estratégias terapêuticas para inibir o crescimento de biofilme produzido por cepas multirresistentes de Pseudomonas aeruginosa representativas de clones e/ou genótipos de resistência endêmicos no Brasil. 2014. 58 f. Dissertação (Mestrado em Microbiologia) - Instituto de Ciências Biomédicas, Universidade de São Paulo, São Paulo, 2014.

Pseudomonas aeruginosa é um patógeno oportunista geneticamente versátil, como evidenciado por seu fenótipo de multirresistência (MR) aos antibacterianos (ATB). A capacidade de produzir um biofilme oferece proteção contra os ATB que possuem efeito bactericida contra sua forma planctônica. $O$ presente estudo avaliou diferentes estratégias terapêuticas contra biofilmes de cepas multirresistentes de $P$. aeruginosa representativas de clones e/ou genótipos de resistência endêmicos no Brasil. Estes biofilmes foram formados in vitro utilizando um modelo adaptado do "MBEC Assay" e as estratégias foram baseadas em: i) uso de bacteriófagos líticos; ii) uso combinado de antibacterianos exibindo atividade sinérgica contra um modelo de crescimento planctônico e; iii) força iônica alta (meio FIA). A combinação dos antibióticos Aztreonam (ATM) e Piperacilina/Tazobactam (PPT), com demonstrado efeito sinérgico para o modelo de crescimento planctônico do clone ST277 (CIM 2/4 $\mu \mathrm{g} / \mathrm{mL}$, $\Sigma F I C=0,265)$, foi incapaz de eliminar o modelo de biofilme $(\mathrm{CIM}>1024 / 1024 \mu \mathrm{g} / \mathrm{mL})$. A linhagem de bacteriófagos líticos ( $\varphi S P M-1)$, com atividade bactericida contra 0 clone ST277 planctônico, não teve atividade bactericida contra o biofilme quando aplicado na concentração de 50 RTD, mesmo quando associado com ATM, PPT ou meio FIA. A aplicação de meio FIA durante a formação do biofilme recuperou o efeito bacteriostático tanto do ATM $(4 \mu \mathrm{g} / \mathrm{mL})$ quanto do PPT $(16 \mu \mathrm{g} / \mathrm{mL})$. A CIM de ambos os antibióticos para o modelo de biofilme formado em condição fisiológica foi também reduzido $(<2 \mu \mathrm{g} / \mathrm{mL})$ quando aplicados em meio FIA. Foi evidenciado que o meio FIA possui um efeito bacteriostático ou bactericida sobre crescimento planctônico, dependente da concentração de $\mathrm{NaCl}$. Contra biofilmes, FIA apresentou atividade bacteriostática que restabeleceu os valores da CIM dos ATB testados.

Palavras-chave: Biofilme. Fagoterapia. Multirresistência. Sinergismo. 


\begin{abstract}
CANTAMESSA, R. G. Therapeutic strategies to inhibit the growth of biofilm produced by strains of multiresistant Pseudomonas aeruginosa representative of clones and/or exhibiting resistance genotypes endemic in Brazil. 2014. 58 p. Masters thesis (Microbiology) - Instituto de Ciências Biomédicas, Universidade de São Paulo, São Paulo, 2014.
\end{abstract}

Pseudomonas aeruginosa is a genetically versatile opportunistic pathogen, as evidenced by their phenotype of multidrug resistance (MDR) to antibiotics (ATB). The ability to produce a biofilm protects against ATB having a bactericidal effect against planktonic form. This study evaluated different therapeutic strategies against biofilms produced by MDR strains of $P$. aeruginosa representative of clones and/or exhibiting resistance genotypes endemic in Brazil. This biofilms were formed in vitro using an adapted MBEC Assay model and the strategies were based on: i) use of lytic bacteriophages; ii) combined use of antibacterials exhibiting a synergistic antimicrobial activity against a planktonic growth model; iii) high ionic strength (HIS medium). The combination of the antibiotics Aztreonam (ATM) and Piperacillin / Tazobactam (PPT) with synergistic effect, as previously demonstrated in the model of clone ST277 planktonic growth (MIC $2.4 \mu \mathrm{g} / \mathrm{mL}, \Sigma F I C=0.265$ ), was unable to eliminate the biofilm growth (MIC> 1024/1024 $\mu \mathrm{g} / \mathrm{mL}$ ). The lineage of lytic bacteriophages ( $\varphi$ SPM-1), with bactericidal activity against planktonic clone ST277, had no bactericidal activity against biofilm when applied at a concentration of 50 RTD, even when associated with ATM, PPT or HIS medium. The application of HIS during biofilm formation restored the bacteriostatic effect of both ATM $(4 \mu \mathrm{g} / \mathrm{mL})$ and PPT $(16 \mu \mathrm{g} / \mathrm{ml})$. The MIC of both antibiotics to biofilm growth in physiological condition was also reduced $(<2 \mu \mathrm{g} / \mathrm{mL})$ by using HIS. It was shown that HIS has a bacteriostatic or bactericidal effect on planktonic growth, which depend on the $\mathrm{NaCl}$ concentration. HIS showed bacteriostatic activity against biofilms, restoring MIC values of the tested ATB.

Keywords: Biofilm. Phage therapy. Multidrug resistance. Synergism. 


\begin{tabular}{cl}
$\mu g$ & Micrograma \\
$\mu \mathrm{L}$ & Microlitro \\
$\mu \mathrm{m}$ & Micrômetro \\
AMI & Amicacina \\
ATCC & American Type Culture Collection \\
ATM & Aztreonam \\
BHI & Brain Heart Infusion \\
CaCl & Cloreto de cálcio \\
CBM & Concentração Bactericida Mínima \\
CIM & Concentração Inibitória Mínima \\
CLSI & Clinical and Laboratory Standards Institute \\
CT & Colistina \\
EDTA & Ácido etilenodiamino tetracético \\
ESBL & Extended Spectrum Beta Lactamase \\
FIA & Força iônica alta \\
FIC & Índice Fracional de Concentração Inibitória \\
GEN & Gentamicina \\
GES & Guiana Extended-Spectrum \\
GIM & German Imipenemase \\
IMP & Imipenem \\
KPC & Klebsiella pneumoniae carbapenemase \\
Mg & Miligrama \\
MHB & Mueller-Hinton Broth \\
MI & Mililitro \\
mM & Milimolar \\
MR & Microrganismo Multirresistente \\
MBL & Metalo-Beta-Lactamase \\
NaCI & Cloreto de sódio \\
Nm & Nanômetro \\
PCR & Polymerase Chain Reaction \\
PPT & Piperacilina/Tazobactam \\
\hline &
\end{tabular}


RTD Routine testing dilution

Rpm Rotações Por Minuto

SPM São Paulo metalo- $\beta$-lactamase

UFC Unidade Formadora de Colônia

UFP Unidade Formadora de Placa

VIM Verona Imipenemase 


\section{LISTA DE ILUSTRAÇÕES}

Fig. 1: Esquema do "MBEC Assay". .30

Fig. 2: Tampas do teste MBEC .31

Fig. 3: Crescimento de biofilme em MHB em comparação com meio MHB+FIA a 7\% de $\mathrm{NaCl}$.

Fig. 4: Crescimento planctônico de diferentes cepas de $P$. aeruginosa produtoras de beta-lactamases (carbapenemases) do tipo SPM (Cepa 48-1997A, ST277), IMP-1, GES-5, VIM (cepa 247B) e KPC-2 (cepa KPC-BH6), em meio MHB suplementado com diferentes concentrações de $\mathrm{NaCl}(3,5-14 \%)$.

Fig. 5: Microscopia eletrônica de cepa de $P$. aeruginosa produtora de betalactamase do tipo GES-5, cultivada em meio MHB suplementado com $7 \%$ de $\mathrm{NaCl}$ 


\section{LISTA DE TABELAS}

Tabela 1. Caracterização das cepas quanto ao fenótipo e genótipo de resistência. . .33

Tabela 2. Determinação da CIM do Aztreonam (ATM) e Piperacilina/Tazobactam (PPT) sobre o modelo de crescimento planctônico e modelo de crescimento em biofilme de $P$. aeruginosa.

Tabela 3. Comparação da $\sum F I C$ da combinação Aztreonam (ATM) e Piperacilina/Tazobactam (PPT) entre o modelo de crescimento planctônico e o modelo de crescimento em biofilme de $P$. aeruginosa. .35

Tabela 4. Testes de sinergismo entre Aztreonam e Piperacilina/Tazobactam contra cepas MRs de $P$. aeruginosa produtora das carbapenemases IMP-1 e GES-5

Tabela 5. Comparação da contagem de UFC em função do tempo em diferentes meios. 37

Tabela 6. Determinação da concentração inibitória (CIM) ou bactericida (CBM) mínima de $\mathrm{NaCl}$ para cepas de $P$. aeruginosa em modelo de crescimento planctônico ou em biofilme. 39

Tabela 7. Avaliação da CIM de ATM e PPT em meios com diferentes concentrações de $\mathrm{NaCl}$. Foi utilizado biofilme da cepa GES-5, formado após 24 horas em MHB e submetido a concentrações crescentes de ATM e PPT (0 a $512 \mu \mathrm{g} / \mathrm{mL}$ ) diluídos em meios $\mathrm{MHB}+\mathrm{FIA}$ de diferentes concentrações $(0 \%$ a $7 \%)$

Tabela 8. Determinação da CIM para biofilmes formados em meio MHB+FIA a 3,5\% e $7 \%$. As concentrações de ATM e PPT variam de 256 a $0,25 \mu \mathrm{g} / \mathrm{mL}$ 
1 INTRODUÇÃO

1.1 A problemática da resistência aos antibacterianos....................................16

1.2 Pseudomonas aeruginosa MR: impacto clínico no Brasil...........................16

1.3 Principais genótipos de Resistência de $P$. aeruginosa e clones endêmicos

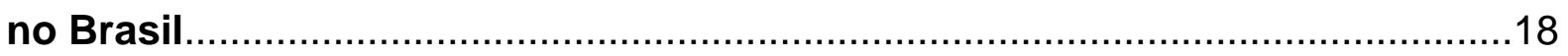

1.4 Pseudomonas aeruginosa e produção de Biofilmes................................19

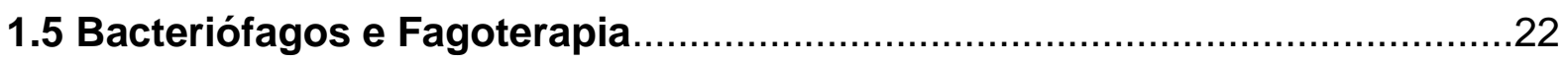

2 OBJETIVOS

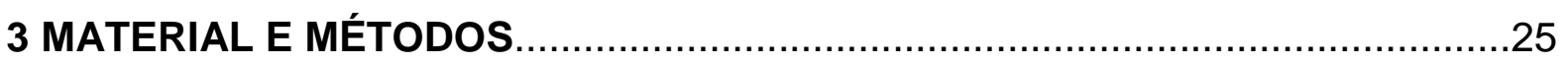

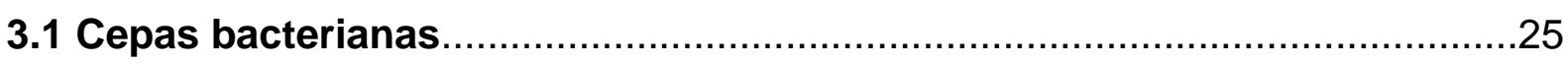

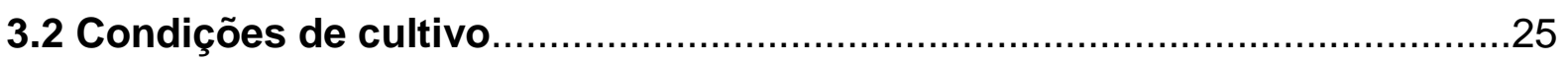

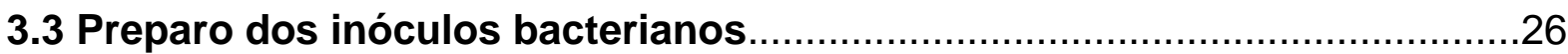

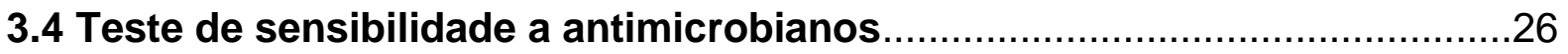

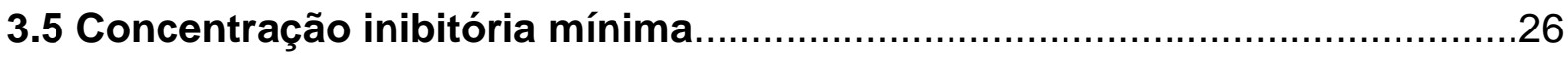

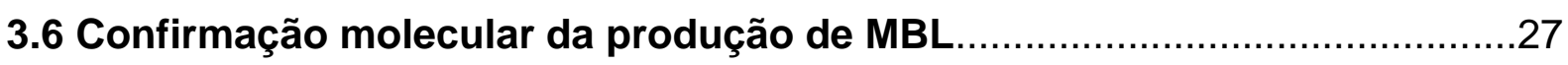

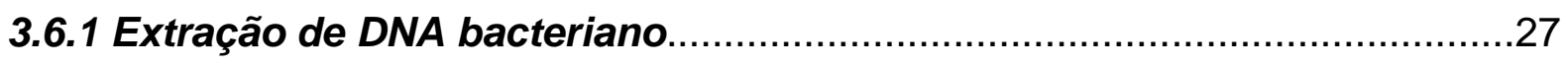

3.6.2 Avaliação da presença dos genes codificadores de MBL.......................27

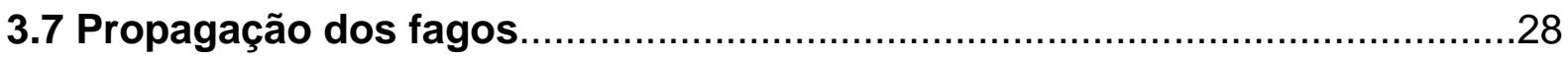

3.8 Titulação dos fagos, determinação RTD (Diluição Teste de Rotina) e 100 RTD

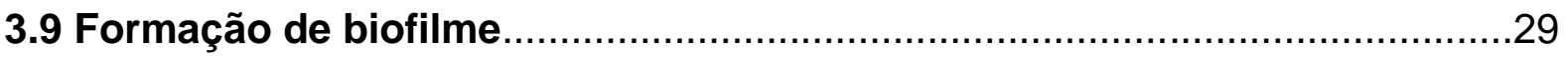

3.10 Atividade antibacteriana contra 0 crescimento bacteriano séssil

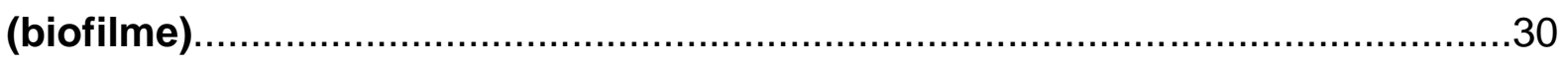

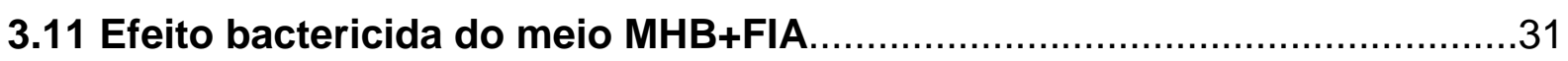

3.12 Combinação de meio FIA com terapias antibacterianas contra o crescimento bacteriano séssil (biofilme) ...........................................................

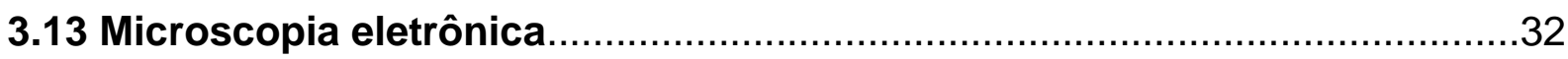

4 RESULTADOS

4.1 Caracterização das cepas.........................................................................33

4.2 Atividade, in vitro, de antibacterianos e bacteriófagos contra o modelo de crescimento em biofilme de P. aeruginosa MR...............................................34 
4.3 Efeito, in vitro, do meio FIA contra o modelo de crescimento em biofilme de $P$. aeruginosa MR e sua associação com antibacterianos e bacteriófagos.......36 4.3.1 Determinação do efeito de meio MHB+FIA sobre cepas de $\boldsymbol{P}$. aeruginosa. .36

4.3.2 Efeito do MHB+FIA na atividade dos antibacterianos aplicados em modelo de crescimento em biofilme de $P$. aeruginosa MR. .39

4.3.3 Uso de meio MHB+FIA como tratamento profilático contra formação de biofilme de $P$. aeruginosa $M R$. 40

4.3.4 Efeito de meio FIA sobre o flagelo de $P$. aeruginosa. .41

5 DISCUSSÃO

5.1 Efeitos de meio de força îônica alta (FIA) no crescimento de $\boldsymbol{P}$. aeruginosa.

5.2 Efeito do biofilme de $P$. aeruginosa MR na terapia de bacteriófagos e de sinergismo .44

5.2.1 Resistência do biofilme de $P$. aeruginosa MR a terapia de bacteriófagos.

5.2.2 Resistência do biofilme de $P$. aeruginosa MR a terapia de sinergismo entre Aztreonam e Piperacilina/Tazobactam. .44

5.3 Uso de meio hipertônico MHB+FIA. 45

5.3.1 Efeito do meio MHB+FIA em cepas de P. aeruginosa. 45

5.3.2 Efeito do meio MHB+FIA na atividade de antibacterianos. .46

5.4 Efeito do meio MHB+FIA na formação do biofilme. .47

5.5 Efeito do meio MHB+FIA na estrutura flagelar de $\boldsymbol{P}$. aeruginosa. .47

6 CONCLUSÕES. .49

REFERÊNCIAS .50 


\section{INTRODUÇÃO}

\subsection{A problemática da resistência aos antibacterianos}

Enquanto novas classes de antibacterianos não foram descobertas nos últimos 30 anos (BOUCHER et al., 2009; LORCH, 1999), o uso excessivo e indiscriminado de antibióticos tradicionais tem contribuído para a seleção de linhagens multirresistentes (MRs) de bactérias clinicamente importantes. Locais relacionados à saúde, como hospitais e clínicas, compõem um ambiente de intensa seleção natural devido ao constante contato com agentes antimicrobianos diversos, estando estas linhagens associadas a infecções hospitalares e altos índices de morbidade e mortalidade (GALES et al., 2003; MOURA; GIR, 2007; SADER et al., 2005).

$\mathrm{Na}$ procura de alternativas terapêuticas, alguns autores têm postulado a utilização de antibióticos clássicos que foram abandonados nos atuais esquemas terapêuticos (LYNCH; WILNER-KRONESH, 2008; PATERSON; LIPMAN, 2007). Porém, uma alternativa mais sustentável é o estudo de combinações de antibióticos que alcancem efeitos sinérgicos (CHOI et al., 2004; GIAMARELLOS-BOURBOULIS; GRECKA; GIAMARELLOU, 1997; KARLOWSKY et al., 2003; PANAGIOTAKOPOULOU; DAIKOS, 2007; SILVA; HIRATA; HIRATA, 2009; SIQUEIRA; DODD; REES, 2003; TRIPODI et al., 2007; ZHANE et al., 2006). Uma ideia mais inovadora contempla a utilização de bacteriófagos líticos, capazes de atacar especificamente as bactérias eliminando reações adversas no hospedeiro.

\subsection{Pseudomonas aeruginosa MR: impacto clínico no Brasil}

Pseudomonas aeruginosa é um bastonete gram-negativo ubíquo de vida livre encontrado em ambientes úmidos, como água, solo, plantas e detritos. Embora raramente cause patologias em indivíduos sadios, é uma grande ameaça a pacientes hospitalizados (DUBOIS et al., 2001). É um patógeno oportunista causador de bacteremias em pacientes imunocomprometidos e em vítimas de queimaduras, causador de infecções urinárias associadas ao uso de cateteres e de pneumonias hospitalares, especialmente em unidades de terapia intensiva (POLLACK, 2000; TSAKRIS et al., 2000). 
Linhagens de $P$. aeruginosa multirresistentes foram recentemente identificadas em hospitais de diversos estados brasileiros, muitas delas com a presença das metalo- $\beta$-lactamases (BRITO et al., 2003; FIGUEIREDO et al., 2007; GONÇALVES et al., 2009; GRÄF; FUENTEFRIA; CORÇÃO, 2008; KOBAYASHI; SADOYAMA; VIEIRA, 2009; LOUREIRO et al., 2002; PIRES et al., 2007; PULCINELLI et al., 2009; SADER et al., 2001). Entre os mecanismos de resistência a carbapenêmicos mais comumente identificados está a produção de $\beta$-lactamases, como, por exemplo, as que pertencem à classe $B$ de Ambler, ou metalo- $\beta$ lactamases $(\mathrm{MBL})$, as quais hidrolisam os beta-lactâmicos comercialmente disponíveis incluindo a sua associação com inibidores de $\beta$-lactamase (i.e., ácido clavulânico). Curiosamente, o único $\beta$-lactâmico não hidrolisado por enzimas do tipo MBL, é o monobactamico aztreonam (MENDES et al., 2006), porém a co-produção de MBL/ESBL parece ser um evento comum principalmente em $K$. pneumoniae, resultando no fenótipo de resistência geral aos beta-lactâmicos (LINCOPAN et al., 2005, 2006).

As MBLs fazem parte de uma classe funcional comum de metalo-enzimas classificadas com base em sua habilidade de hidrolisar o imipenem em um nível mensurável, e em sua característica de serem inibidas por íons de metal quelante, como o EDTA, assim como em sua ausência de suscetibilidade aos inibidores de $\beta$ lactamases disponíveis comercialmente (FILHO et al., 2002; MENDES et al., 2006).

Desde o início da década de 1990, novos genes que codificam MBL têm sido descritos em patógenos clinicamente importantes, como Pseudomonas spp., Acinetobacter spp. e membros da família Enterobacteriaceae (MENDES et al., 2006). Esses genes que codificam MBLs foram encontrados inseridos em estruturas genéticas, denominadas integrons, que fornecem mobilidade ao gene (PICÃO et al., 2008).

Inicialmente, na América Latina, MBLs foram encontradas exclusivamente em espécies de bactérias não fermentadoras como Pseudomonas spp. e Acinetobacter spp. (WALSH et al., 2005). As enzimas IMP e VIM têm sido relatadas esporadicamente desde 2001 nestas bactérias, sendo que a enzima SPM-1 (até agora exclusiva de Pseudomonas aeruginosa) tem sido extensamente disseminada entre hospitais brasileiros (GALES et al., 2003).

A primeira identificação da enzima SPM-1 metalo- $\beta$-lactamase ocorreu na cidade de São Paulo, Brasil. Desde o seu primeiro relato em clones de 
Pseudomonas aeruginosa produtora de SPM-1 ocorreu elevada mortalidade entre os pacientes hospitalizados (GALES et al., 2003; QUEENAN; BUSH, 2007; SANTOS FILHO et al., 2002).

O gene que codifica SPM-1 parece estar especificamente relacionado à espécie de Pseudomonas aeruginosa, uma vez que, até o momento, não foi detectada em nenhum outro Microrganismo nosocomial. A prevalência da produção de MBL em Pseudomonas aeruginosa, uma das principais causas de infecção nosocomial, têm aumentado em muitos países do Sudeste da Ásia, Europa e América Latina (MENDES et al., 2006; ZAVASCKI et al., 2006). O fenótipo SPM-1 não hidrolisa aztreonam, in vitro, e aparentemente, a piperacilina associada ao tazobactam pode apresentar alguma atividade sinérgica (GALES et al., 2003; WALSH et al., 2005).

Espécies de $\mathrm{MBL}$ positiva são usualmente resistentes a $\beta$-lactâmicos, aminoglicosídeos e fluoroquinolonas, entretanto permanecem sensíveis à polimixina. Assim, a terapia apropriada para o tratamento dessas infecções permanece escassa e é digna de avaliação (WALSH et al., 2005).

\subsection{Principais genótipos de resistência de $P$. aeruginosa e clones endêmicos no Brasil}

O principal mecanismo de resistência aos beta-lactâmicos em $P$. aeruginosa está associado com a produção de enzimas do tipo carbapenemase, as quais se diferenciam em serino-enzimas e metalo-enzimas. No primeiro grupo encontram-se carbapenemases de classe A, representados pela Guiana Extended-Spectrum (GES) $\beta$-lactamase, que inclui as variantes GES-2, GES-4, GES-5, GES-6 e GES-18, e pelas enzimas do tipo KPC. Genes codificando $\beta$-lactamase do tipo GES tem sido isolados de diversos membros de Enterobacteriaceae e $P$. aeruginosa, sendo encontrados no sudeste asiático, América do Sul, África e Europa (WALSH, 2008). No Brasil, variantes GES tem sido identificadas em K. pneumoniae e $P$. aeruginosa em diferentes estados (DA FONSECA et al., 2007; DROPA et al., 2010; PELLEGRINO et al., 2006; PICÃO et al., 2010; POLOTTO et al., 2012; RIBEIRO et al., 2014).

Com relação as carbapenemases do tipo KPC, variantes KPC-2 e KPC-5 tem sido identificadas em $P$. aeruginosa isoladas em Colombia, Puerto Rico, Trinidad e 
Tobago, EUA, China, Brasil e Argentina (AKPAKA et al., 2009; GE et al., 2011; JÁCOME et al., 2012; PASTERÁN et al., 2012; POIREL et al., 2010; VILLEGAS et al., 2007; WOLTER et al., 2009). Enquanto todos os dados obtidos de enterobactérias sugerem que bla $a_{\mathrm{KPC}}$ é plasmidial, os dados obtidos em $P$. aeruginosa sugerem uma localização cromossômica (WALSH, 2008).

Isolados produtores de metalo-beta-lactamase (MBL), classificas como classe B de Ambler, são capazes de degradar todos os beta-lactâmicos, a exceção do aztreonam. Dentre as variantes identificadas no Brasil, encontram-se enzimas do tipo imipenem (IMP), Verona Integron-Encoded Metallo-Beta-Lactamase (VIM) e Sãa Paulo Mello-beta-lactamase (SPM-1). Apesar dos três tipos terem sido detectados em hospitais brasileiros, SPM-1 está presente em até $70 \%$ dos isolados clínicos e é considerado endêmico no Brasil (NEVES et al., 2011; WALSH, 2008).

\subsection{Pseudomonas aeruginosa e produção de Biofilmes}

Uma característica que confere considerável proteção a estes microrganismos é a capacidade de formar um biofilme, o que permite a sobrevivência das bactérias em ambientes hostis. Biofilme bacteriano pode ser definido como uma comunidade estruturada de células bacterianas aderidas a uma superfície viva ou inerte e envoltas por uma matriz polimérica (COSTERTON et al., 1999; HARPER; ENRIGHT, 2011).

Biofilmes constituem um modo protegido de crescimento, que permite a sobrevivência de bactérias em ambientes hostis. As estruturas que formam 0 biofilme contêm canais por onde os nutrientes podem circular (DE BEER; SRINIVASAN; STEWART, 1994), e células em diferentes regiões de um biofilme exibem diferentes padrões de expressão gênica (DAVIES; CHAKRABARTY; GEESEY, 1993). Estas comunidades sésseis podem dar origem a indivíduos planctônicos, os quais são capazes de se dispersar e rapidamente multiplicar-se. Considerando que bactérias planctônicas estão expostas a bacteriófagos, a antibióticos e ao sistema imune de hospedeiros, não é de surpreender que muitas espécies causadoras de doenças crônicas possuam biofilmes envolvidos em sua infecção, a qual não é tratada facilmente usando as terapias antibióticas convencionais (COSTERTON et al., 1999; DONLAN, 2011). 
Infecções envolvendo biofilmes dividem algumas características clínicas, afetando principalmente indivíduos comprometidos imunologicamente. Biofilmes desenvolvem-se preferencialmente em superfícies inertes, ou tecido morto, e ocorrem mais comumente em dispositivos médicos (LAMBE et al., 1991); também podem se formar em tecido vivo, como no caso de endocardite. Possuem crescimento lento, em uma ou mais localidades, e normalmente demoram a produzir sintomas evidentes (WARD et al., 1992). Bactérias sésseis liberam antígenos que estimulam a produção de anticorpos, mas estes não são eficientes em matar as bactérias no biofilme (COCHRANE et al., 1988).

Mesmo em indivíduos imunologicamente competentes, infecções com biofilme raramente são superadas usando-se apenas o sistema imune do hospedeiro (KHOURY et al., 1992). A terapia antibiótica típica reverte os sintomas causados pelas células planctônicas liberadas do biofilme, mas falha em destruir o próprio biofilme (MARRIE; NELLIGAN; COSTERTON, 1982). Dessa forma, infecções com biofilmes, tipicamente mostram sintomas recorrentes, tratados com ciclos de antibióticos até que toda a população séssil seja removida (COSTERTON; STEWART; GREENBERG, 1995).

Uma das mais importantes características de biofilmes bacterianos é sua resistência a agentes antimicrobianos. Bactérias vivendo em biofilmes podem ser até mil vezes mais resistentes a componentes antibacterianos do que bactérias planctônicas (NICKEL et al., 1985), indicando que mecanismos de resistência das bactérias planctônicas podem diferir dos mecanismos de bactérias no biofilme. Além disso, resultados recentes sugerem que a resistência de biofilmes é multifatorial, pois apenas uma combinação de diferentes mecanismos poderia justificar os níveis de resistência observados em comunidades de biofilme (DRENKARD, 2003).

Considerando-se que comunidades de biofilme são caracterizadas por justaposição de células bacterianas envolvidas por uma matriz de exopolissacarídeo, muitos autores tem sugerido que o biofilme pode representar uma barreira física para a ação de antibióticos, mas os resultados ainda são contraditórios (DE BEER; SRINIVASAN; STEWART, 1994; HUANG et al., 1995; SUCl et al., 1994; VRANY; STEWART; SUCI, 1997). Estudos mais recentes mostraram que apesar de tetraciclina ser capaz de rapidamente penetrar e alcançar todas as células dentro de um biofilme de Escherichia coli, estas células ainda eram mais resistentes a tetraciclina do que células planctônicas (STONE et al., 2002). Padrões espaciais da 
ação de antibióticos mostraram que a morte de bactérias não aumentou em áreas penetradas por antibióticos, indicando que limitação de transporte não tem papel significativo na sobrevivência do biofilme (DRENKARD, et al., 2003). Interessantemente, autores descobriram que antibióticos eram capazes de matar apenas as bactérias localizadas em zonas com elevada atividade metabólica e concentração de oxigênio, sugerindo que limitação de oxigênio e baixa atividade metabólica eram mais relevantes para a tolerância do biofilme (WALTERS III et al., 2003).

No caso de bacteriófagos a situação é um pouco diferente, visto que polímeros extracelulares e alterações na membrana celular podem impedir o acesso do vírus a superfície bacteriana. $\mathrm{Na}$ ausência de enzimas, podem existir barreiras físicas a superfície de ao menos uma porção das bactérias. Conforme o biofilme envelhece e células morrem ou são liberadas, novos receptores virais em potencial tornam-se acessíveis à infecção (SUTHERLAND et al., 2004). Apesar de alguns fagos poderem carregar em sua superfície enzimas capazes de degradar polissacarídeos bacterianos, elas são muito específicas e dificilmente agem em mais do que algumas estruturas polissacarídicas proximamente relacionadas (SUTHERLAND, 1995, 1999). Outros fatores que podem influenciar a retenção de fagos dentro de biofilmes são as interações hidrofóbicas e eletrostáticas. $\mathrm{Na}$ interação de colifagos com membranas tanto hidrofóbicas quanto hidrofílicas, seu ponto isoelétrico foi um fator crítico na interação com o biofilme (VAN VOORTHUIZEN; ASHBOULT; SCHÄFER, 2001).

Diferenças na densidade bacteriana que compõem o biofilme determinam gradientes na disponibilidade de nutrientes e de oxigênio. Estas diferenças dentro do biofilme resultam em diferenças na atividade metabólica das bactérias, causando uma heterogeneidade na população (DRENKARD et al., 2003). Estudos realizados sobre padrões de crescimento bacteriano e atividade metabólica confirmaram a presença de bactérias em lento crescimento ou fase estacionária dentro dos biofilmes (STERNBERG et al., 1999; XU et al., 1998; WENTLAND et al., 1996). Enquanto alguns estudos revelaram que a ação bactericida de beta-lactâmicos contra biofilmes de $P$. aeruginosa é significantemente afetada quando em crescimento lento, a ação bactericida de fluoroquinolonas independe da taxa de crescimento nos biofilmes celulares (TANAKA et al. 1999). Também foi relatado que 
crescimento lento na $P$. aeruginosa afeta a resistência à tetraciclina, mas não afeta resistência a tobramicina (BROOUN; LIU; LEWIS, 2000).

Mesmo após serem encontradas diferenças na resistência a ciprofloxacina entre $P$. aeruginosa em biofilmes e em bactérias planctônicas em fase exponencial, não se encontrou diferença significativa entre a resistência de bactérias em biofilme e bactérias planctônicas em fase estacionária (EVANS et al. 1991). Este resultado sugere que apesar da redução na velocidade de crescimento contribuir para a baixa suscetibilidade a antimicrobianos, este fator sozinho não explica as diferenças observadas na resistência entre bactérias planctônicas e em biofilmes (DRENKARD, 2003).

\subsection{Bacteriófagos e Fagoterapia}

Bacteriófagos são vírus que se multiplicam seletivamente em bactérias e a fagoterapia é um método que utiliza os bacteriófagos como agentes terapêuticos para o tratamento de infecções bacterianas (BETTS; VASSE; HOCHBERG , 2013; COOPER; DENYER; MAILLARD, 2013; ESSOH et al., 2013; HENRY; LAVIGNE; DEBARBIEUX, 2013; SOOTHILL et al., 2013; ZHANG; HUNT; HU, 2013). A principal vantagem do uso dos bacteriófagos em comparação aos quimioterápicos e antibióticos é sua grande capacidade de replicação. Como qualquer outro vírus, cada célula infectada libera uma grande quantidade de novos vírus capazes de infectar outras bactérias (CARLTON, 1999). Essa característica sugere que uma única dose de fagos pode ser suficiente no combate a uma infecção. Além disso, o uso da fagoterapia proporciona redução no aparecimento de novas cepas resistentes aos antibióticos e, dado o seu mecanismo de ação, elimina somente cepas bacterianas específicas, não ocorrendo alterações na microbiota presente (SMITH; HUGGINS, 1982).

No caso de bacteriófagos líticos, a expressão de genes precoces proporciona a síntese de enzimas necessárias à duplicação de seu material genético seguida pela formação de proteínas para a composição de partículas virais. Finalmente ocorre a síntese de peptídeos que formam poros e causam o rompimento das estruturas da membrana bacteriana com a consequente liberação de inúmeras cópias do bacteriófago no meio externo. Os bacteriófagos parecem ser preferencialmente específicos para um hospedeiro (LEVINE, 1992), mas 
bacteriófagos líticos para várias bactérias de espécies diferentes foram descritos, e provavelmente exerçam papel importante na ecologia de microorganismos e na transferência de genes entre espécies (JENSEN et al., 1998).

A ocorrência de isolados clínicos resistentes a múltiplos antibióticos fez com que a fagoterapia como alternativa terapêutica às infecções bacterianas fosse revitalizada, com experimentos aplicados na clínica médica (ANDREATTI FILHO et al., 2007; CISLO et al., 1987; DEBARBIEUX et al., 2010; FIORENTIN; VIEIRA; BARIONI, 2005; KUMARI; HARJAI; CHHIBBER, 2009; MCVAY; VELÁSQUEZ; FRALICK, 2007; MERABISHVILI et al., 2009; PAISANO et al., 2004; SOOTHILL et al., 1992; SOUSA et al., 2010; TRAVIS et al., 2000; WANG et al., 2006). No Brasil, a estratégia de fagoterapia tem sido direcionada para avaliar atividade bactericida contra Shigella spp., Salmonella spp. e Enterococcus faecalis (ANDREATTI FILHO et al., 2007; PAISANO et al., 2004; SOUSA et al., 2010).

A interação entre biofilmes e bacteriófagos ainda não é clara. Apesar da matriz polimérica ser uma barreira mecânica potencialmente capaz de impedir o acesso dos vírus as bactérias, é possível que o biofilme atue como um reservatório para os fagos e, conforme o biofilme envelhece e células morrem ou são liberadas, novos receptores virais em potencial tornem-se acessíveis a infecção (SUTHERLAND et al., 2004).

Em vista desses fatos, maiores estudos em relação à terapia bacteriofágica tornam-se necessários para que seja possível introduzir uma alternativa terapêutica mais efetiva no que concerne às infecções ocasionadas por bactérias multirresistente, as quais geralmente não respondem aos atuais esquemas terapêuticos baseados no uso de antibióticos de amplo espectro comercialmente disponíveis. 


\section{OBJETIVOS}

O presente estudo teve como objetivo avaliar diferentes estratégias terapêuticas contra a forma de crescimento séssil (biofilme) de cepas multirresistentes de $P$. aeruginosa representativas de clones e/ou genótipos de resistência endêmicos no Brasil, tendo como objetivos específicos:

1. Avaliar a atividade de bacteriófagos líticos ( $\varphi S P M-1)$, com atividade comprovada contra modelos planctônicos de $P$. aeruginosa MR, contra a forma de crescimento em biofilme;

2. Avaliar a atividade de combinações de antibióticos, com comprovado efeito sinérgico contra modelos planctônicos de $P$. aeruginosa MR, contra a forma de crescimento em biofilme;

3. Avaliar condições físico-químicas que possam inibir a forma de crescimento em biofilme, e seu efeito associado ao uso de antibacterianos e bacteriófagos. 


\section{MATERIAL E MÉTODOS}

\subsection{Cepas bacterianas}

Foram utilizados 14 isolados clínicos de Pseudomonas aeruginosa, clonalmente não relacionados e com perfil de resistência ao imipenem. Estes isolados foram recuperados de uma coleção proveniente de um estudo multicêntrico (NEVES, 2010). Adicionalmente, foram utilizadas cepas de referência representativa de clones e/ou genótipos de resistência endêmicos no Brasil, incluindo as cepas $P$. aeruginosa BH6, produtora de KPC-2 (Profa. Ana Lúcia da Costa Darini, FCF-USPRP); P. aeruginosa produtora de GIM-1, IMP-1 (319 EPM), SPM-1 ST277 (481997A) (Profa. Ana C. Gales, EPM-UNIFESP); P. aeruginosa produtora de GES-5 (Profa. Mara C. Nogueira); e a cepa co-produtora de SPM-1 e metilase RmtD PA0905 (Profa. Doroti Garcia de Oliveira, IAL-SP). O perfil de MR com ênfase na resistência aos carbapenêmicos foi verificado pela metodologia de difusão do disco (Kirby-Bauer), seguindo as normas padronizadas pelo CLSI (2009, 2014). Como controles, foram utilizadas as cepas $P$. aeruginosa ATCC 27853, $P$. aeruginosa PA01 (Profa. Sílvia F. Costa, Laboratório de Bacteriologia, HC, FMUSP), E. coli ATCC 25922 e E. coli ATCC 35218.

\subsection{Condições de cultivo}

Os isolados clínicos e as cepas de referência foram semeadas em $3 \mathrm{~mL}$ de caldo BHI (Merck, Darmstad-Alemanha) e incubadas a $37^{\circ} \mathrm{C}$ durante 18 a 20 horas, sob agitação constante em agitador rotativo (modelo CT-712 RN, Cientec, Piracicaba, Brasil) a $150 \mathrm{rpm}$. Em seguida, foram semeadas superficialmente em ágar Mac Conkey (Merck, Darmstad-Alemanha) e incubadas por 24 horas em estufa bacteriológica (modelo 002-CB, Fanem, SP, Brasil) a $37^{\circ} \mathrm{C}$. As colônias dessa semeadura foram utilizadas para extração de DNA e para preservação a -20 ${ }^{\circ} \mathrm{C}$ e a $80 \stackrel{\circ}{\circ}$ em $20 \%$ de glicerol. 


\subsection{Preparo dos inóculos bacterianos}

Inóculos bacterianos padronizados $\left(5 \times 10^{8} \mathrm{UFC} / \mathrm{mL}\right)$ foram preparados a partir do cultivo dos isolados em $3 \mathrm{~mL}$ de caldo Müeller-Hinton (Difco) e incubados a $37 \stackrel{\circ}{\mathrm{C}}$ em agitador rotativo a $150 \mathrm{rpm}$ durante 4 a 5 horas, fase de crescimento exponencial da bactéria. A turbidez da cultura foi ajustada para a escala 0,5 de McFarland, confirmada através da leitura da absorbância entre 0,08 e 0,12 dos tubos contendo a suspensão bacteriana, em espectrofotômetro (Quimis, Brazil), a comprimento de onda de $625 \mathrm{~nm}$.

\subsection{Teste de sensibilidade a antimicrobianos}

Os antibiogramas foram realizados utilizando o método de Kirby-Bauer, estabelecido pelo CLSI (2009), a fim de obter o perfil de resistência para os antibióticos imipenem (10 $\mu \mathrm{g})$, meropenem (10 $\mu \mathrm{g})$, ceftazidima $(30 \mu \mathrm{g})$, amicacina $(30 \mu \mathrm{g})$, ciprofloxacina $(5 \mu \mathrm{g})$, aztreonam $(30 \mu \mathrm{g})$, piperacilina/tazobactam (100/10 $\mu \mathrm{g})$, cefepima $(30 \mu \mathrm{g})$, gentamicina $(10 \mu \mathrm{g})$ e colistina $(10 \mu \mathrm{g})$. O CLSI (2014) foi utilizado para definir os valores de resistência.

\subsection{Concentração inibitória mínima}

Os testes de concentração inibitória mínima (CIM) foram realizados pela técnica de diluição em caldo, seguindo as padronizações estabelecidas pelo CLSI 2009. O antimicrobiano foi testado em concentrações decrescentes, geralmente de $1024 \mu \mathrm{g} / \mathrm{mL}$ a $0,03 \mu \mathrm{g} / \mathrm{mL}$ (dupla diluição seriada). Como controle foram utilizadas as cepas P. aeruginosa ATCC 27853; E. coli ATCC 25922 e E. coli ATCC 35218.

Foi também utilizado um indicador fluorescente/colorimétrico com propriedade redox, Alamar Blue® (também denominado resazurina) (Sigma Chemical Co, St. Louis, USA) para confirmar a atividade bactericida. O Alamar Blue foi preparado segundo Nateche e colaboradores (2006), e $30 \mu \mathrm{L}$ da solução foram adicionados em cada poço da microplaca, sendo posteriormente incubada. A leitura foi feita 24 horas depois, e interpretada como a mínima concentração do antimicrobiano em diluição produzindo inibição do crescimento macroscopicamente visível, sendo a forma 
oxidada azul (célula não viável/não fluorescente) e a forma reduzida rosa (célula viável/fluorescente).

\subsection{Confirmação molecular da produção de MBL}

\subsubsection{Extração de DNA bacteriano}

Para extração do DNA total, foi utilizado o método de fervura (CHAPMAN, et al., 2001). A partir de um inóculo bacteriano padronizado $\left(1 \times 10^{8} \mathrm{UFC} / \mathrm{mL}\right)$ semeado em caldo Mueller-Hinton e mantido em agitador rotativo a $37^{\circ} \mathrm{C}$ por 18 a 20 horas a $150 \mathrm{rpm}$, alíquotas de $1 \mathrm{~mL}$ foram submetidas à centrifugação durante 1 minuto a 16.000 G (Eppendorf, 5804 R, USA). O sobrenadante foi descartado e o sedimento obtido foi novamente suspenso em $100 \mu \mathrm{L}$ de água Milli-Q (Millipore, Bedford, MA, EUA), estéril. As suspensões foram fervidas a $95^{\circ} \mathrm{C}$, durante 10 minutos, em banhomaria (modelo 247, Nova Técnica, SP, Brasil). Após 5 minutos de centrifugação a 7.500 G (Eppendorf, 5804 R, USA), $100 \mu \mathrm{L}$ de cada sobrenadante foram transferidos para um novo microtubo estéril e congelados a $-20{ }^{\circ} \mathrm{C}$.

Como controle interno da extração, as amostras de DNA obtidas foram submetidas à PCR utilizando-se os primers para pesquisa da subunidade de DNA ribossomal 16S (DA SILVA FILHO et al., 2004). As condições de ciclagem foram as seguintes: incubação inicial a $94{ }^{\circ} \mathrm{C}$ por 5 min, 30 ciclos a $94{ }^{\circ} \mathrm{C}$ por 1 min, $56{ }^{\circ} \mathrm{C}$ por 1 min e $72{ }^{\circ} \mathrm{C}$ por $1 \mathrm{~min}$, seguidos por extensão final a $72{ }^{\circ} \mathrm{C}$ por $5 \mathrm{~min}$.

\subsubsection{Avaliação da presença dos genes codificadores de MBL}

A confirmação molecular da produção de MBL foi realizada por PCR utilizando primers para amplificar os genes das variantes IMP, GIM, VIM e SPM (BALSALOBRE et al., 2009; GALES et al., 2003; NISHIO et al., 2004; POIREL; COLLET; NORDMANN, 2000). As condições de ciclagem foram as seguintes: desnaturação a $94{ }^{\circ} \mathrm{C}$ por 5 minutos, 30 ciclos a $94 \stackrel{\circ}{\mathrm{C}}$ por 1 minuto, anelamento a $50-55^{\circ} \mathrm{C}$ por 1 minuto e extensão a $72 \stackrel{\circ}{ } \mathrm{C}$ por 1 minuto, seguidos de uma extensão final a $72 \stackrel{\circ}{\circ}$ por 5 minutos. 


\subsection{Propagação dos fagos}

Bacteriófagos ( $\varphi S P M-1$ ) foram obtidos de uma coleção de fagos coletada em rios urbanos em São Paulo, Brasil. A propagação dos fagos é realizada inicialmente pelo método de ágar semi-sólido e, em seguida, é utilizado o método de propagação estoque. Uma colônia pura de cada cepa propagadora é cultivada em $2 \mathrm{~mL}$ de caldo TSB-CaCl${ }_{2}$, e incubada a $37^{\circ} \mathrm{C}$ overnight. Após este período, uma diluição de 1:20 do caldo é incubada por 1 a 2 horas, sendo adicionados $200 \mu \mathrm{L}$ do fago ( $\varphi$ SPM-1) após 6 horas de incubação a $30^{\circ} \mathrm{C}$ sob agitação. Os fagos são centrifugados a $12.000 \mathrm{G}$ por $30 \mathrm{~min}$ a $4{ }^{\circ} \mathrm{C}$. O sobrenadante é filtrado através de filtros de membrana com porosidade de 0,22 $\mu \mathrm{m}$. Após essa etapa, os fagos são coletados em tubos estéreis para o armazenamento a $4{ }^{\circ} \mathrm{C}$. Um controle de esterilidade dos fagos é realizado usando $10 \mu \mathrm{L}$ de fago filtrado, semeados em ágar Mueller-Hinton acrescido de $\mathrm{CaCl}_{2}$, seguido de incubação a $37^{\circ} \mathrm{C}$ por 24 horas (BERGAN, 1978).

\subsection{Titulação dos fagos, determinação RTD (Diluição Teste de Rotina) e 100 RTD}

A titulação dos fagos é realizada conforme descrito por Bergan (1978). O fago ( $\varphi$ SPM-1), pertencente à família Myoviridae (NEVES et al., 2011, 2014), foi diluído sucessivamente na proporção de $10^{-1}$ a $10^{-7}$ unidades formadoras de placa $(\mathrm{UFP}) / \mathrm{mL}$, em caldo TSB-CaCl 2 . Cada cepa propagadora, previamente cultivada em TSB-CaCl 2 e com turbidez equivalente à escala 0,5 de McFarland, foi semeada por inundação na superfície das placas de Petri contendo ágar $\mathrm{MHB}-\mathrm{CaCl}_{2}$. As placas são secas à temperatura ambiente por $5 \mathrm{~min}$. Em seguida, uma gota de 0,02 $\mathrm{mL}$ de cada diluição do fago foi aplicada na placa de ágar sendo incubada a $30{ }^{\circ} \mathrm{C}$ overnight. A atividade do fago foi confirmada pela presença de placas de lise típicas. O RTD e o 100 RTD são determinados após a diluição do fago ao mais alto nível contável de unidades formadoras de placa (T). A RTD consiste na diluição de cada fago que provoca lise confluente na respectiva cepa propagadora, ou seja, uma escala abaixo da lise confluente (lise total das células no local de aplicação dos fagos). De acordo com esse critério, o título do fago corresponde à: T (placa de lise contável) × 50 × 10 × (diluição na qual foi possível contar o maior número de placas de lise) (BERGAN, 1978). 


\subsection{Formação de biofilme}

A sobrevivência do biofilme é testada utilizando-se uma adaptação do "MBEC Assay" (previamente conhecido como Calgary Biofilm Device) (CERY et al.,1999). O teste utiliza tampas específicas para a formação de um biofilme capaz de ser transferido entre diferentes microplacas de 96 poços (Fig. 1). Isso permite comparar o desempenho de diferentes tratamentos, detectando se eliminaram não só as bactérias planctônicas como também bactérias que formaram biofilme nos "pegs" fixados na tampa. Foram testados diferentes estágios do biofilme, comparando se os tratamentos são eficientes mesmo contra biofilmes crescidos em 12 e 24 horas, a $37^{\circ} \mathrm{C}$ e agitação de $100 \mathrm{rpm}$.

São testados biofilmes formados tanto em meio Mueller-Hinton caldo normal (meio MHB) quanto formado em meio acrescido de $\mathrm{NaCl}$ em diferentes concentrações ( $\mathrm{NaCl}$ utilizado foi $7 \%$, exceto quando especificado o contrário), considerado um meio de força iônica alta (meio MHB+FIA).

$O$ teste MBEC possui algumas falhas, como a passagem de uma superfície ar/água pelo biofilme durante a transferência entre duas placas. Mesmo assim, seus benefícios superam essas deficiências: é um teste prático e rápido, permitindo avaliar diversas condições simultaneamente; os resultados das CIM obtidas para biofilme são facilmente comparáveis com os obtidos em testes com bactérias planctônicas.

Este modelo foi considerado o mais adequado para a seleção dos tratamentos mais eficientes, de forma a minimizar as combinações testadas em animais durante projetos futuros. 


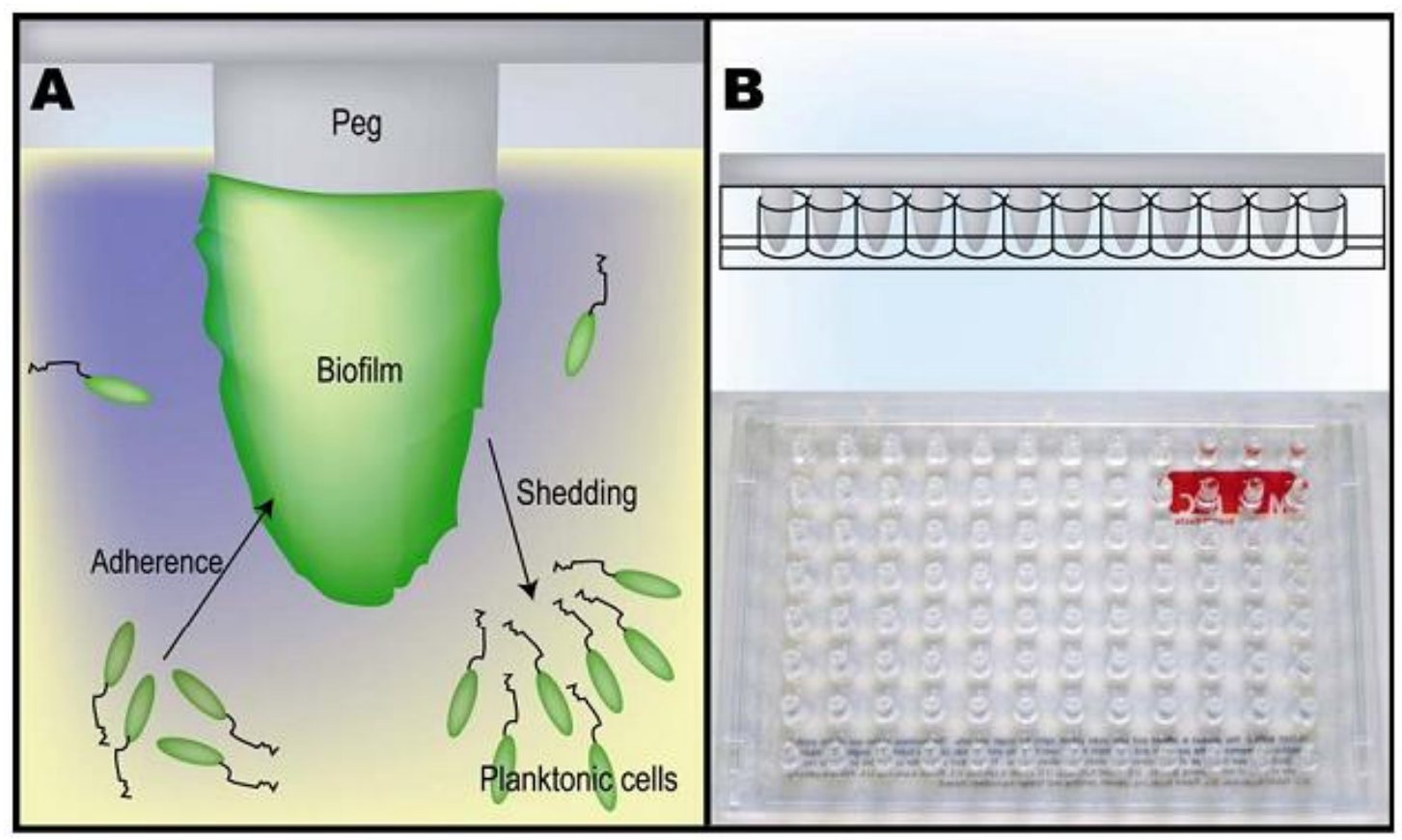

Fig. 1: Esquema do "MBEC Assay". A) Biofilmes formam-se nas ponteiras de poliestireno da tampa, quando bactérias planctônicas aderem a superfície. Biofilmes são envoltos por um "muco", o qual pode ser visível a olho nú. Células planctônicas também se desprendem do biofilme, o que serve como inóculo para determinação de CIM. B) A tampa possui 96 ponteiras de plástico (pegs) idênticas e encaixa numa placa padrão de 96 poços. Adaptado de "The MBEC ${ }^{T M}$ Physiology \& Genetics (P\&G) Assay", oferecido pela Innovotech.

\subsection{Atividade antibacteriana contra o crescimento bacteriano séssil (biofilme).}

Pegs contendo biofilmes provenientes de 12 e 24 horas de crescimento (Fig. 2) foram transferidos para microplacas de 96 poços, preenchidas por meios adicionados com diferentes antibióticos nas concentrações apropriadas à determinação da CIM (1024 a 0,03 $\mu \mathrm{g} / \mathrm{mL}$ ). Após mais 24 horas de incubação a $37{ }^{\circ} \mathrm{C}$, as tampas foram transferidas para uma nova microplaca contendo caldo Mueller-Hinton, para confirmação do efeito bactericida. Uma suspensão de Alamarblue foi utilizada para confirmar o crescimento bacteriano indetectável a olho nu. $\mathrm{Na}$ presença de bactérias viáveis, esse corante, originalmente de cor azul, é convertido para um tom rosado. Com o objetivo de detectar até mesmo as bactérias mais profundamente localizadas no biofilme, essa placa é sonicada por $10 \mathrm{~min}$ para garantir que o biofilme seja rompido e solte das ponteiras. 


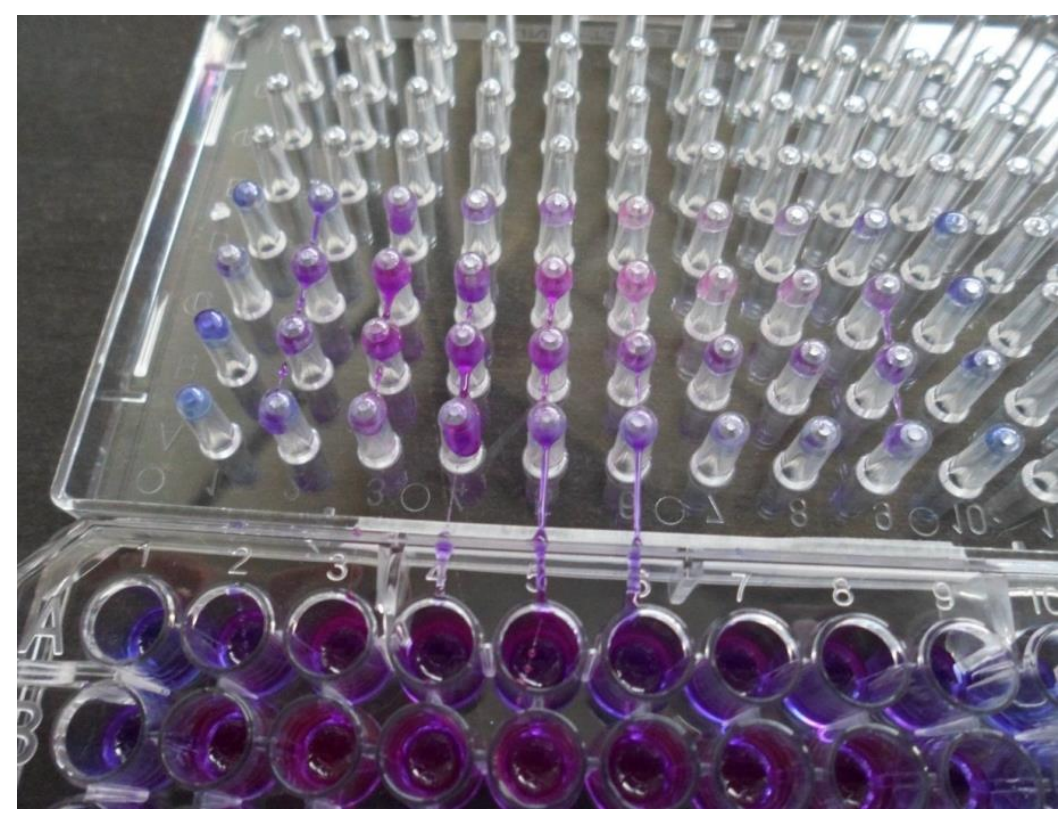

Fig. 2: Tampas do teste MBEC. É possível observar o biofilme "mucoide" aderido nas extremidades das "pegs".

O teste de sinergismo foi realizado através de microplacas com combinações crescentes de dois antibióticos em conjunto, um em cada eixo da placa. O cálculo do FIC, resultante da soma de (CIM da combinação/CIM antibiótico $A)+(C I M)$ combinação/CIM antibiótico $B$ ) permite distinguir se existe ou não um efeito sinérgico nas várias combinações utilizadas no projeto (HALL; MIDDLETON; WESTMACOTT, 1983).

A atividade dos fagos foi medida em conjunto com concentrações crescentes de Aztreonam e Piperacilina/Tazobactam, sendo aplicados $10 \mu \mathrm{L}$ do fago a 10 RTD.

\subsection{Efeito bactericida do meio MHB+FIA}

Para avaliar o efeito da força iônica, tanto sobre o crescimento planctônico como sobre o crescimento em biofilme, o caldo MHB utilizado foi ajustado com diferentes concentrações de $\mathrm{NaCl}(3,5$ - 14,0\%). A atividade bacteriostática e/ou bactericida do meio $\mathrm{MHB}+\mathrm{FIA}$ foi avaliada pela contagem de unidades formadoras de colônia (UFC), sendo realizadas no tempo 0h, e após 2 e 12 horas de interação. Esta estratégia foi baseada em um trabalho reportando o efeito inibitório de uma solução hipertônica de sal sobre a motilidade de $P$. aeruginosa (HAVASI et al., 2008), 
fenômeno previamente reportado para E. coli (LI; ADLER, 1993; SHI; LOUISE; ADLER, 1993).

\subsection{Combinação de meio FIA com terapias antibacterianas contra o crescimento bacteriano séssil (biofilme)}

A combinação de antibacterianos com meio MHB+FIA foi avaliada utilizando a mesma metodologia do "MBEC Assay", alterando a concentração do meio em que o biofilme é formado e a concentração do meio em que o antibacteriano é diluído, ambas variando de $\mathrm{NaCl} 3,5 \%$ (meio $\mathrm{MHB}$ ) até $\mathrm{NaCl} 14 \%$.

\subsection{Microscopia eletrônica}

As bactérias foram cultivadas em meio $\mathrm{MHB}$ e MHB+FIA com concentração de $\mathrm{NaCl}$ igual a $7 \%$ durante 24 horas. A preparação para microscopia foi realizada segundo Oliveira e colaboradores (OLIVEIRA et al., 2009). 


\section{RESULTADOS}

\subsection{Caracterização das cepas}

Os resultados da caracterização das cepas utilizadas no estudo são apresentados na tabela 1 .

Tabela 1. Caracterização das cepas quanto ao fenótipo e genótipo de resistência.

\begin{tabular}{|c|c|c|c|c|c|c|c|c|c|c|c|c|c|}
\hline \multicolumn{14}{|c|}{ Cepas de $P$. aeruginosa } \\
\hline 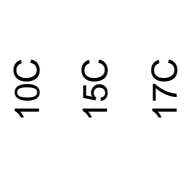 & $\stackrel{\oplus}{\square}$ & 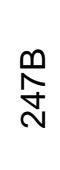 & 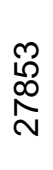 & 옴 & $\frac{0}{m}$ & $\begin{array}{l}\text { ర్ల } \\
\text { D }\end{array}$ & O & 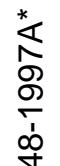 & $\begin{array}{l}\text { م } \\
\text { ஸٌ } \\
\text { ய }\end{array}$ & $\begin{array}{l}\text { ơ } \\
\text { 口 } \\
0 \\
0 \\
\mathbf{1}\end{array}$ & 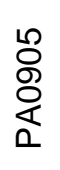 & $\sum_{0}^{\overline{1}}$ & $\stackrel{\bar{\prime}}{\underline{a^{\prime}}}$ \\
\hline
\end{tabular}

\begin{tabular}{|c|c|c|c|c|c|c|c|c|c|c|c|c|c|c|c|c|}
\hline \multicolumn{17}{|l|}{ Antibiograma } \\
\hline Imipenem & $\mathbf{R}$ & $\mathbf{R}$ & $\mathbf{R}$ & $\bar{R}$ & $\bar{R}$ & $S$ & $S$ & $\mathbf{R}$ & $\bar{R}$ & $\overline{\mathbf{R}}$ & $\overline{\mathbf{R}}$ & $\mathbf{R}$ & $\bar{S}$ & $\mathbf{R}$ & $\mathbf{R}$ & $\bar{R}$ \\
\hline Ciprofloxacina & $\mathbf{R}$ & $\mathbf{R}$ & $\mathbf{R}$ & $\mathbf{R}$ & $\mathbf{R}$ & $S$ & $S$ & $\mathbf{R}$ & $\mathbf{R}$ & $\mathbf{R}$ & $\mathbf{R}$ & $\mathbf{R}$ & $\mathbf{R}$ & $\mathbf{R}$ & $\mathbf{R}$ & $\mathbf{R}$ \\
\hline Gentamicina & $\mathbf{R}$ & $\mathbf{R}$ & $\mathbf{R}$ & $\mathbf{R}$ & $\mathbf{R}$ & $S$ & $S$ & $\mathbf{R}$ & $\mathbf{R}$ & $\mathbf{R}$ & $\mathbf{R}$ & $\mathbf{R}$ & $\mathbf{R}$ & $\mathbf{R}$ & $\mathbf{R}$ & $\mathbf{R}$ \\
\hline Ceftazidima & $\mathbf{R}$ & $\mathbf{R}$ & $\mathbf{R}$ & $\mathbf{R}$ & $\mathbf{R}$ & $S$ & $S$ & $\mathbf{R}$ & $\mathbf{R}$ & $\mathbf{R}$ & $\mathbf{R}$ & $\mathbf{R}$ & $\mathbf{R}$ & $\mathbf{R}$ & $\mathbf{R}$ & $\mathbf{R}$ \\
\hline Aztreonam & S & $\mathbf{R}$ & I & $S$ & $\mathbf{R}$ & $S$ & $S$ & S & $S$ & $S$ & $\mathrm{~S}$ & $\mathbf{R}$ & $\mathbf{R}$ & $\mathbf{R}$ & $\mathbf{R}$ & $S$ \\
\hline Piperacilina/Tazobactam & $\mathrm{S}$ & 1 & $\mathbf{R}$ & $\mathbf{R}$ & $\mathbf{I}$ & $S$ & $S$ & $S$ & $\mathbf{R}$ & $\mathbf{R}$ & $\mathrm{S}$ & $\mathbf{R}$ & $\mathbf{I}$ & $\mathbf{R}$ & $\mathbf{R}$ & $\mathbf{I}$ \\
\hline Meropenem & $\mathbf{R}$ & $\mathbf{R}$ & $\mathbf{R}$ & $\mathbf{R}$ & $\mathbf{R}$ & $S$ & $S$ & $\mathbf{R}$ & $\mathbf{R}$ & $\mathbf{R}$ & $\mathbf{R}$ & $\mathbf{R}$ & $S$ & $\mathbf{R}$ & $\mathbf{R}$ & $\mathbf{R}$ \\
\hline Cefepima & $\mathbf{R}$ & $\mathbf{R}$ & $\mathbf{R}$ & $\mathbf{R}$ & $\mathbf{R}$ & $S$ & $S$ & $\mathbf{R}$ & $\mathbf{R}$ & $\mathbf{R}$ & $\mathbf{R}$ & $\mathbf{R}$ & $S$ & $\mathbf{R}$ & $\mathbf{R}$ & $\mathbf{R}$ \\
\hline Amicacina & $\mathbf{R}$ & $\mathbf{R}$ & $\mathbf{R}$ & $\mathbf{R}$ & $S$ & $S$ & $S$ & $\mathbf{R}$ & $\mathbf{R}$ & $\mathbf{R}$ & I & $\mathbf{R}$ & $S$ & I & $S$ & $\mathbf{R}$ \\
\hline Colistina & $S$ & $\mathbf{R}$ & $\mathbf{R}$ & $S$ & $S$ & $S$ & $S$ & $S$ & $S$ & $S$ & $\mathrm{~S}$ & $\mathbf{R}$ & $\mathbf{R}$ & $\mathbf{R}$ & $\mathbf{R}$ & $\mathbf{R}$ \\
\hline \multicolumn{17}{|l|}{ Genótipo de Resistência } \\
\hline bla $a_{\mathrm{MP}}$ & - & - & - & - & - & - & - & - & - & - & - & - & - & - & - & + \\
\hline blavIM & - & - & - & - & + & - & - & - & - & - & - & - & - & - & - & - \\
\hline bla & + & + & + & + & - & - & - & + & + & + & + & - & - & + & - & - \\
\hline$b / a_{\mathrm{GIM}}$ & - & - & - & - & - & - & - & - & - & - & - & - & - & - & + & - \\
\hline$b l a_{\mathrm{GES}}$ & - & - & - & - & - & - & - & - & - & - & - & + & - & - & - & - \\
\hline$b / a_{\mathrm{KPC}}$ & - & - & - & - & - & - & - & - & - & - & - & - & + & - & - & - \\
\hline$R m t D$ & + & + & + & + & - & - & - & + & + & + & + & - & - & + & - & - \\
\hline
\end{tabular}

* Clone endêmico brasileiro ST277. S = Sensível; I = intermediário; R = resistente; (+) gene presente; (-) gene ausente; Interpretação segundo os padrões definidos pelo CLSI 2014.

A maioria das cepas apresentou resistência ao imipenem e a outras classes de antibacterianos, caracterizando um fenótipo de multirresistência (MAGIORAKUS et al., 2012). Os antibióticos que apresentaram atividade, in vitro, foram: Aztreonam (ATM), Piperacilia/Tazobactam (PPT), Colistina (CT) e Amicacina (AMI). 


\subsection{Atividade, in vitro, de antibacterianos e bacteriófagos contra o modelo de crescimento em biofilme de $P$. aeruginosa MR}

Foram investigadas as possíveis diferenças das CIMs dos antibacterianos ATM e PPT, quando avaliados no modelo de crescimento planctônico e no modelo de crescimento em biofilme (tabela 2).

Tabela 2. Determinação da CIM do Aztreonam (ATM) e Piperacilina/Tazobactam (PPT) sobre o modelo de crescimento planctônico e modelo de crescimento em biofilme de $P$. aeruginosa.

\begin{tabular}{lcccc}
\hline \multirow{2}{*}{ Cepa } & \multicolumn{4}{c}{ CIM $(\mu \mathrm{g} / \mathrm{mL})$} \\
& Crescimento planctônico & Crescimento em biofilme \\
\cline { 2 - 5 } & ATM & PPT & ATM & PPT \\
\hline 10C & 16 & 128 & $\geq 256$ & $\geq 256$ \\
$15 \mathrm{C}$ & 16 & $\geq 256$ & $\geq 256$ & $\geq 256$ \\
17C & 16 & 32 & $\geq 256$ & $\geq 256$ \\
31C & 8 & $\geq 256$ & $\geq 256$ & $\geq 256$ \\
36C & 8 & 128 & $\geq 256$ & $\geq 256$ \\
44C & 8 & $\geq 256$ & $\geq 256$ & $\geq 256$ \\
111B & 16 & 128 & $\geq 256$ & $\geq 256$ \\
247B & 32 & 32 & $\geq 256$ & $\geq 256$ \\
48-1997A (ST277) & 4 & 64 & $\geq 256$ & $\geq 256$ \\
GES-5 & 64 & 128 & $\geq 256$ & $\geq 256$ \\
IMP-1 & 4 & 32 & $\geq 256$ & $\geq 256$ \\
KPC-BH6 & 16 & 128 & $\geq 256$ & $\geq 256$ \\
GIM-1 & 16 & $\geq 256$ & $\geq 256$ & $\geq 256$ \\
PA0905 & 8 & $\geq 256$ & $\geq 256$ & $\geq 256$ \\
E. coli ATCC 25922 & 0,03 & 0,25 & - & - \\
\hline
\end{tabular}

Uma vez que a combinação ATM/PPT foi previamente confirmada em nosso laboratório como sinérgica para modelos planctônicos de $P$. aeruginosa MRs produtora de MBLs (TURANO, 2012), nosso primeiro objetivo foi confirmar se esse sinergismo poderia ser extrapolado para modelos de biofilme. Os testes preliminares foram realizados com a cepa 48-1997A, já caracterizada como possuindo o perfil alélico ST277, representativa do clone endêmico brasileiro (SILVA et al., 2011).

Foi avaliado o sinergismo entre ATM e PPT utilizando desde as concentrações limites correspondentes ao ponto de corte que define sensibilidade in vitro (8 e $16 \mu \mathrm{g} / \mathrm{mL}$, respectivamente), até concentrações elevadas (1024 $\mu \mathrm{g} / \mathrm{mL}$ para 
cada antibiótico). A combinação ATM/PPT foi testada contra as cepas 10C, 31C, 36C, 44C, 247B, GIM-1 e 48-1997A (ST277), em modelo de biofilme (Tabela 3). Em condições normais (i.e. em casos onde um biofilme cresce por 24 horas apenas em $\mathrm{MHB}$ ), não foi observado nenhum efeito clinicamente sinérgico para a combinação ATM/PPT.

Tabela 3. Comparação da $\sum$ FIC da combinação Aztreonam (ATM) e Piperacilina/Tazobactam (PPT) entre o modelo de crescimento planctônico e o modelo de crescimento em biofilme de $P$. aeruginosa.

$$
\sum \mathrm{FIC}^{*}
$$

Cepa Crescimento planctônico Crescimento em biofilme

\begin{tabular}{ccc}
\hline $10 \mathrm{C}$ & 0,375 & 2 \\
$31 \mathrm{C}$ & 0,5 & 2 \\
$36 \mathrm{C}$ & 0,28 & 2 \\
$44 \mathrm{C}$ & 0,5 & 2 \\
$247 \mathrm{~B}$ & 0,5 & 2 \\
$48-1997 \mathrm{~A}$ (ST277) & 0,265 & 2 \\
GIM-1 & 0,5 & 2
\end{tabular}

* $O$ efeito sinérgico foi definido pelo $\sum \mathrm{FIC}<0,5$; indiferente $=\sum \mathrm{FIC}>0,5 \mathrm{e}<4$; antagonismo quando $\sum$ FIC > 4 (HALL; MIDDLETON; WESTMACOTT, 1983).

Para as cepas produtoras das beta-lactamases IMP-1 ou GES-5 não foi observado nenhum efeito sinérgico, mesmo em condições de crescimento planctônico (tabela 4), demonstrando a necessidade de avaliar novas alternativas terapêuticas.

Tabela 4. Testes de sinergismo entre Aztreonam e Piperacilina/Tazobactam contra cepas MRs de $P$. aeruginosa produtora das carbapenemases IMP-1 e GES-5.

\begin{tabular}{lc}
\hline $\begin{array}{l}\text { Cepa } P . \\
\text { aeruginosa }\end{array}$ & $\sum \mathrm{FIC}^{*}$ \\
\hline IMP-1 & 0,75 \\
GES-5 & 0,632
\end{tabular}

* $O$ efeito sinérgico foi definido pelo $\overline{\sum F I C<0,5 \text {; indiferente }=\sum \mathrm{FIC}}>0,5 \mathrm{e}<4$; antagonismo quando $\Sigma$ FIC > 4 (HALL; MIDDLETON; WESTMACOTT, 1983).

O bacteriófago do tipo ( $\varphi$ SPM-1) foi avaliado na concentração de 50 RTD, tanto sozinho quanto em conjunto com diversas concentrações de Aztreonam e Piperacilina/Tazobactam, sobre o biofilme formado pela cepa 48-1997A (ST277) após 24 horas de crescimento em MHB. Essa concentração de bacteriófagos não teve efeito sobre a redução da CIM dos antibióticos (ambos apresentando uma CIM 
> $1024 \mu \mathrm{g} / \mathrm{mL}$ ) e também não foi capaz de eliminar o biofilme quando administrado sozinho.

4.3 Efeito, in vitro, do meio FIA contra o modelo de crescimento em biofilme de $P$. aeruginosa MR e sua associação com antibacterianos e bacteriófagos

\subsubsection{Determinação do efeito de meio MHB+FIA sobre cepas de $P$. aeruginosa}

Avaliamos os efeitos de meio MHB+FIA durante a formação de biofilmes. Nossa expectativa era de que as altas concentrações de $\mathrm{NaCl}$ fossem capazes de prejudicar a formação de biofilme ou mesmo atuar em biofilmes já consolidados.

A cepa PA01 foi mantida em MHB normal (linhas A-D) e MHB+FIA (linhas EF) durante 24 horas antes das ponteiras serem transferidas para uma placa com MHB normal e serem submetidas a sonicação. A figura 3 demonstra a diferença entre biofilmes formados nas ponteiras em MHB ou em MHB+FIA.

Nossos resultados iniciais não encontraram apenas uma redução na formação de biofilmes em meio MHB+FIA, mas também "pegs" onde não foram detectadas bactérias (Fig. 3). Contudo, este teste não esclarece se o meio MHB+FIA teve um efeito bactericida ou apenas afetou a formação de biofilmes.

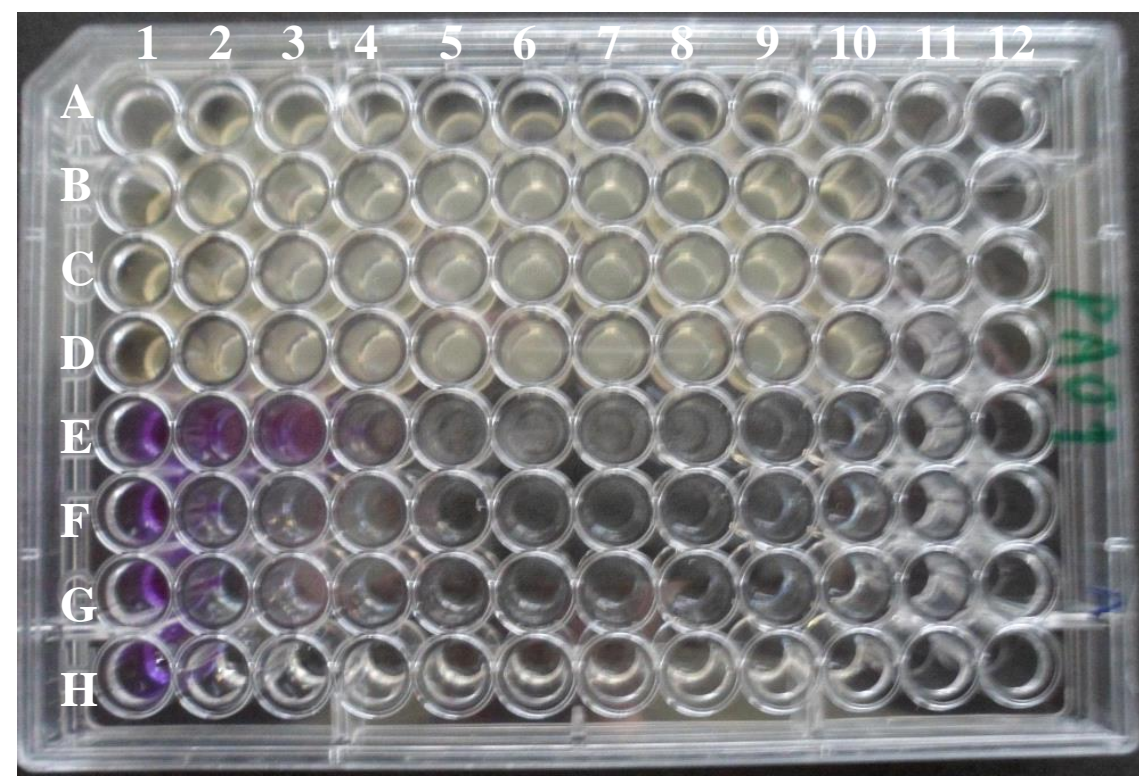

Fig. 3: Crescimento de biofilme em MHB (linhas A-D) em comparação com meio MHB+FIA a 7\% de $\mathrm{NaCl}$ (linhas E-F F). O corante Alamar-Blue foi adicionado após 24 horas de incubação. A cepa testada corresponde a $P$. aeruginosa PA01. Cada linha vertical (1-10) corresponde a um inóculo de 1 $\times 10^{5}$ ufc/mL da cepa de $P$. aeruginosa PA01. Linhas 11 e 12 não contém inóculo bacteriano. 
Em uma próxima etapa, foi avaliada a possibilidade de um efeito bactericida do meio FIA contra bactérias em modelo planctônico. Para discernir se existe esse efeito bactericida, fizemos uma contagem de Unidades Formadoras de Colônias (UFC) presentes em meio MHB e em meio MHB+FIA em função do tempo. Dependendo da cepa, o meio MHB+FIA demonstrou ter efeito bactericida ou bacteriostático (tabela 5 ).

Tabela 5. Comparação da contagem de UFC em função do tempo em diferentes meios.

\begin{tabular}{lllll}
\hline \multirow{2}{*}{$\begin{array}{l}\text { Tempo de interação } \\
\text { (h) }\end{array}$} & \multicolumn{2}{l}{$\begin{array}{l}\text { Contagem de células viáveis }(\mathrm{UFC} / \mathrm{mL}) \\
\text { Cepa 48-1997A, SPM-1 } \\
(\mathrm{ST} 277)\end{array}$} & $\begin{array}{l}\text { Cepa produtora de } \\
\text { GES-5 }\end{array}$ \\
\cline { 2 - 5 } & MHB & MHB+FIA & MHB & MHB+FIA \\
\hline 0 & $3 \times 10^{5}$ & $3 \times 10^{5}$ & $1 \times 10^{5}$ & $4 \times 10^{5}$ \\
2 & $3 \times 10^{6}$ & $2 \times 10^{4}$ & $2 \times 10^{\prime}$ & $3 \times 10^{5}$ \\
12 & $3 \times 10^{12}$ & 0 & $3 \times 10^{13}$ & $3 \times 10^{5}$ \\
\hline
\end{tabular}

Após confirmar a atividade de uma concentração fixa de $\mathrm{NaCl} 7 \%$, determinamos a concentração inibitória mínima (CIM) e a concentração bactericida mínima (CBM), sobre os modelos de crescimento planctônico e em biofilme, para as 14 cepas (Fig. 4). 


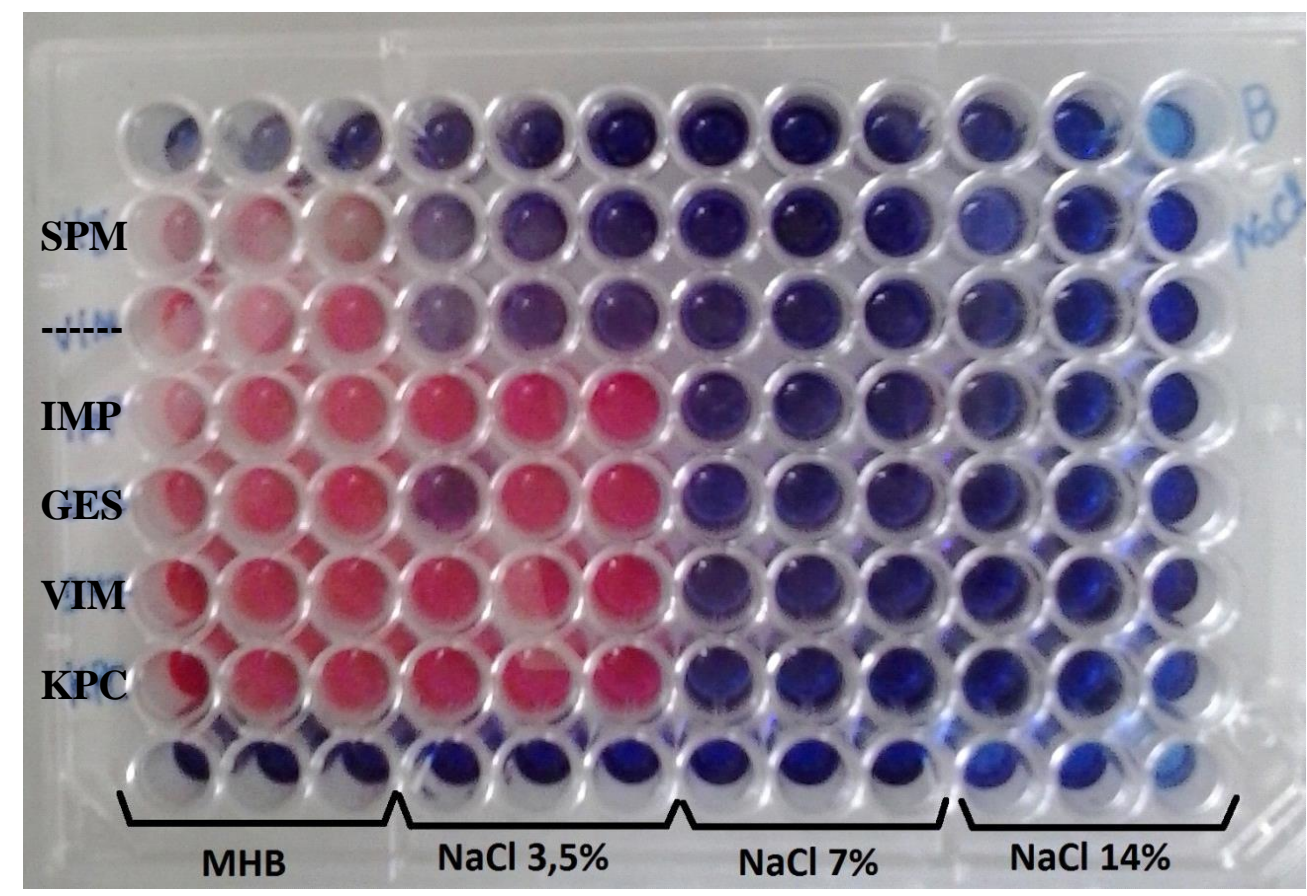

Fig. 4: Crescimento planctônico de diferentes cepas de $P$. aeruginosa produtoras de beta-lactamases (carbapenemases) do tipo SPM (Cepa 48-1997A, ST277), IMP-1, GES-5, VIM (cepa 247B) e KPC-2 (cepa KPC-BH6), em meio MHB suplementado com diferentes concentrações de $\mathrm{NaCl}(3,5-14 \%)$. Após 24 de incubação foi adicionada uma suspensão ao 0,001\% de Alamar-Blue.

A tabela 6 demonstra que o meio $\mathrm{MHB}+\mathrm{FIA}$ apresentou efeito bactericida apenas contra as cepas em modelo de crescimento planctônico, eliminando 10 das 14 cepas. A concentração bactericida mínima do $\mathrm{NaCl}$ variou entre 7 e 14\%, dependendo da cepa utilizada. O modelo de crescimento em biofilme demonstrou ser resistente contra o efeito bactericida do meio MHB+FIA, sobrevivendo mesmo quando exposto a concentração de $\mathrm{NaCl}$ a $14 \%$. 
Tabela 6. Determinação da concentração inibitória (CIM) ou bactericida (CBM) mínima de $\mathrm{NaCl}$ para cepas de $P$. aeruginosa em modelo de crescimento planctônico ou em biofilme. Os valores foram expressos em porcentagem (\%).

\begin{tabular}{|c|c|c|c|c|}
\hline \multirow{3}{*}{ Cepa (genótipo) } & \multicolumn{4}{|c|}{ Meio FIA ( $\mathrm{NaCl} \%)$} \\
\hline & \multicolumn{2}{|c|}{ CIM } & \multicolumn{2}{|c|}{ CBM } \\
\hline & Planctônico & Biofilme & Planctônico & Biofilme \\
\hline $10 \mathrm{C}\left(\mathrm{b} / a_{\mathrm{SPM}-1} / r m t D\right)$ & 7 & 7 & 14 & $>14$ \\
\hline $15 \mathrm{C}\left(b / a_{\mathrm{SPM}-1} / r m t D\right)$ & 7 & 7 & 14 & $>14$ \\
\hline $17 \mathrm{C}\left(b / a_{\mathrm{SPM}-1} / r m t D\right)$ & 7 & 7 & 14 & $>14$ \\
\hline $31 \mathrm{C}\left(\mathrm{b} / a_{\mathrm{SPM}-1} / r m t D\right)$ & 7 & 7 & 14 & $>14$ \\
\hline $36 \mathrm{C}\left(b / a_{\mathrm{SPM}-1} / r m t D\right)$ & 7 & 7 & 14 & $>14$ \\
\hline 44C (b/asPM-1 $/ r m t D)$ & 7 & 7 & 14 & $>14$ \\
\hline 111B (b/a SPM- $1 / r m t D)$ & 7 & 7 & 14 & $>14$ \\
\hline 247B (blavIM-1 $)$ & 7 & 7 & 14 & $>14$ \\
\hline 48-1997A (bla SPM-1, $\mathrm{ST} 277)$ & 3,5 & 7 & 7 & $>14$ \\
\hline GES-5 (b/a $\left.a_{\mathrm{GES}-5}\right)$ & 7 & 7 & $>14$ & $>14$ \\
\hline IMP-1 (bla $\left.\left.\right|_{\mid M P-1}\right)$ & 7 & 7 & $>14$ & $>14$ \\
\hline KPC-BH6 (bla KPC-2 $)$ & 7 & 7 & $>14$ & $>14$ \\
\hline GIM-1 (b/a $\left.a_{\mathrm{GIM}-1}\right)$ & 7 & 7 & 14 & $>14$ \\
\hline PA0905 (blasPM-1 $/ r m t D)$ & 7 & 7 & $>14$ & $>14$ \\
\hline
\end{tabular}

Enquanto o efeito bactericida apresentou variações, o efeito bacteriostático foi muito mais uniforme entre as diferentes cepas e modelos testados. Uma concentração de $7 \%$ de $\mathrm{NaCl}$ foi capaz de inibir o crescimento de todas as amostras, tanto em modelo planctônico quanto em modelo de biofilme.

\subsubsection{Efeito do MHB+FIA na atividade dos antibacterianos aplicados em modelo de crescimento em biofilme de $P$. aeruginosa MR}

Considerando o meio MHB+FIA um eficaz agente bacteriostático e possível agente bactericida, comparamos o efeito de diferentes concentrações de $\mathrm{NaCl}$ combinadas com crescentes concentrações de ATM e de PPT.

O biofilme da cepa GES- 5 foi formado durante 24 horas em MHB. Em seguida, os biofilmes foram transferidos para meio composto por concentrações crescentes de antibacterianos e de $\mathrm{NaCl}$ (tabela 7).

A combinação de meio FIA com antibacterianos ou bacteriófagos não produziu nenhum efeito detectável contra biofilmes já consolidados: a única 
concentração capaz de inibir o crescimento bacteriano continua a ser $\mathrm{NaCl}$ a $7 \%$, mesmo na ausência de ATM ou PPT, e a adição de antibacterianos ou vírus não alterou o efeito do meio FIA de bacteriostático para bactericida.

Tabela 7. Avaliação da CIM de ATM e PPT em meios com diferentes concentrações de $\mathrm{NaCl}$. Foi utilizado biofilme da cepa GES-5, formado após 24 horas em MHB e submetido a concentrações crescentes de ATM e PPT ( 0 a $512 \mu \mathrm{g} / \mathrm{mL}$ ) diluídos em meios MHB+FIA de diferentes concentrações $(0 \%$ a $7 \%)$. O fago ( $\varphi$ SPM-1) foi aplicado a 50 RTD em crescentes concentrações de $\mathrm{NaCl}$. (-) indica ausência de atividade bacteriostática ou bactericida. Os valores estão em $\mu \mathrm{g} / \mathrm{mL}$. *

\begin{tabular}{llll}
\hline $\begin{array}{l}\text { Concentração de NaCl em meio } \\
\text { MHB+FIA }\end{array}$ & CIM ATM & CIM PPT & $\begin{array}{l}\text { Efeito Fago } \\
(\varphi S P M-1)\end{array}$ \\
\hline MHB normal & $>512$ & $>512$ & - \\
MHB+FIA 3,5\% & $>512$ & $>512$ & - \\
MHB+FIA 5\% & $>512$ & $>512$ & - \\
MHB+FIA 7\% & 0 & 0 & Bacteriostático \\
\hline
\end{tabular}

${ }^{*} \mathrm{ATM}=$ Aztreonam; PPT $=$ Piperacilina/Tazobactam.

\subsubsection{Uso de meio MHB+FIA como tratamento profilático contra formação de biofilme de $P$. aeruginosa MR}

Considerando o efeito bacteriostático do meio MHB+FIA tanto contra o modelo planctônico como contra o modelo de biofilmes, avaliamos se a FIA teria algum efeito profilático se utilizada antes da formação do biofilme.

As bactérias das cepas GES-5, IMP-1, KPC-BH6 e PA0905 foram inoculadas em meio $\mathrm{MHB}$ com $\mathrm{NaCl}$ a $3,5 \%$ ou a 7\%. Após 24 horas, as ponteiras foram transferidas para meios MHB com concentrações crescentes de ATM ou PPT (tabela 8). 
Tabela 8. Determinação da CIM para biofilmes formados em meio MHB+FIA a $3,5 \%$ e $7 \%$. As concentrações de ATM e PPT variam de 256 a $0,25 \mu \mathrm{g} / \mathrm{mL}$. Todos os valores estão em $\mu \mathrm{g} / \mathrm{mL}$. ${ }^{*}$

\begin{tabular}{|c|c|c|c|c|}
\hline \multirow{3}{*}{ Cepa (genótipo) } & \multicolumn{4}{|c|}{ Meio de formação do biofilme } \\
\hline & \multicolumn{2}{|c|}{$\mathrm{MHB}+\mathrm{FIA} \mathrm{3,5 \%}$} & \multicolumn{2}{|c|}{$\mathrm{MHB}+\mathrm{FIA} \mathrm{7 \%}$} \\
\hline & CIM ATM & CIM PPT & CIM ATM & CIM PPT \\
\hline GES-5 (b/a $\left.a_{G E S-5}\right)$ & $>256$ & $>256$ & 8 & 16 \\
\hline IMP-1 (b/a|MP-1 $)$ & $>256$ & $>256$ & 8 & 16 \\
\hline KPC-BH6 (bla $\left.{ }_{K P C-2}\right)$ & 32 & 128 & 4 & 8 \\
\hline PA0905 (bla SPM-1 $/ r m t D)$ & $>256$ & $>256$ & 8 & 16 \\
\hline
\end{tabular}

* ATM = Aztreonam; PPT = Piperacilina/Tazobactam.

A aplicação do meio $\mathrm{MHB}+\mathrm{FIA}$ a $7 \%$ antes da formação do biofilme reduziu a CIM tanto de ATM quanto de PPT para valores encontrados em bactérias planctônicas.

\subsubsection{Efeito de meio FIA sobre o flagelo de P. aeruginosa}

Imagens obtidas com microscopia eletrônica demonstram que os flagelos estão presentes em $P$. aeruginosa cultivadas em meio $\mathrm{MHB}$ com $7 \%$ de $\mathrm{NaCl}$ (Fig. 5). 


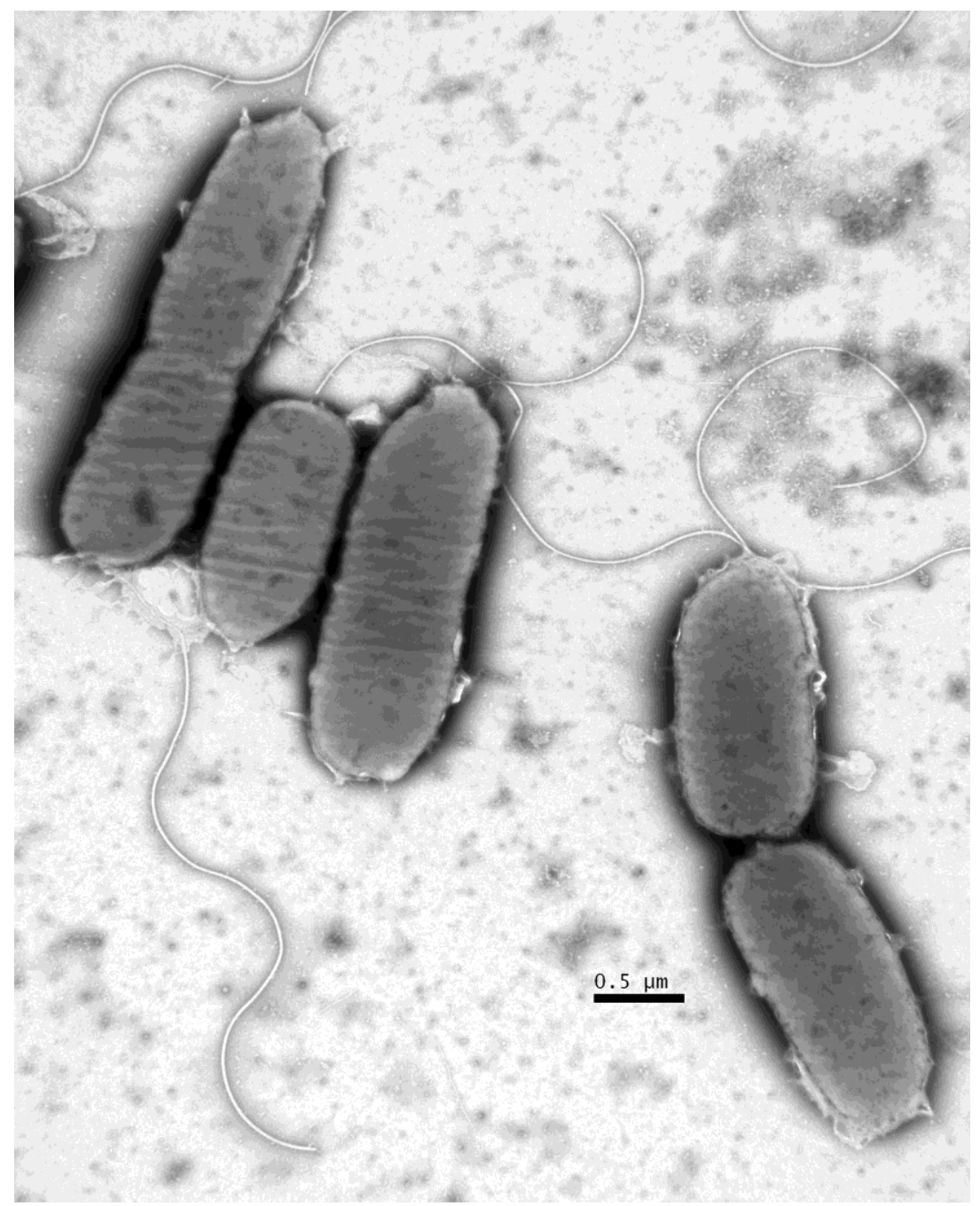

Fig. 5: Microscopia eletrônica de cepa de $P$. aeruginosa produtora de beta-lactamase do tipo GES-5, cultivada em meio MHB suplementado com $7 \%$ de $\mathrm{NaCl}$. 


\section{DISCUSSÃO}

\subsection{Efeitos de meio de força îônica alta (FIA) no crescimento de $P$. aeruginosa}

Baseado em um levantamento bibliográfico extensivo, visando à procura de uma estratégia efetiva contra o modelo de crescimento em biofilme, utilizamos, como alternativa, o uso de meio de caldo Mueller-Hinton suplementado com $\mathrm{NaCl}$ a $7 \%$, considerado um meio de força iônica alta (FIA) e denominado meio MHB+FIA. Trabalhos recentes relataram o uso de soluções salinas hipertônicas ( $\mathrm{NaCl} 7 \%)$ como uma boa alternativa no tratamento de fibrose cística causada por $P$. aeruginosa (HAVASI et al., 2008), possivelmente afetando a síntese de flagelo e prejudicando a motilidade de $P$. aeruginosa. No estudo de Havasi e colaboradores, embora não foi demonstrado, foi sugerida a possibilidade de um efeito contra o crescimento em biofilme de uma solução hipertônico, uma vez que este ambiente poderia regular a síntese ou expressão do biofilme, assim como, a inibição do flagelo. A inibição do flagelo poderia ter um efeito sobre o tamanho da população bacteriana capaz de aderir ao substrato e iniciar a formação do biofilme.

De fato, Michon e colaboradores descreveram não somente uma redução na motilidade de $P$. aeruginosa quando expostas a soluções hipersalinas $(\mathrm{NaCl} 2 \%)$ como também um efeito bactericida em concentrações mais elevadas $(\mathrm{NaCl} 10 \%)$ (Michon et al., 2014).

Possíveis efeitos da força iônica incluem afetar o potencial de equilíbrio da membrana externa de uma bactéria gram-negativa ou de produzir alterações eletrolíticas mediadas por mudanças osmóticas. Sendo assim, talvez a administração de bacteriófagos ou antibióticos em solução hipersalina possa ser uma boa combinação para eliminar biofilmes já consolidados ou como tratamento profilático. 


\subsection{Efeito do biofilme de $P$. aeruginosa MR na terapia de bacteriófagos e de sinergismo}

\subsubsection{Resistência do biofilme de P. aeruginosa MR a terapia de bacteriófagos}

A presença do biofilme impediu que o bacteriófago ( $\varphi S P M-1)$, capaz de eliminar as cepas testadas em modelo planctônico (NEVES et al., 2011), erradicasse a população bacteriana em modelo de biofilme.

O biofilme não impede completamente a difusão de bacteriófagos através de sua matriz e pode ser considerado um possível reservatório para os bacteriófagos, os quais permaneceriam capazes de infectar as bactérias que se desprendessem do biofilme (ABEDON, 2012; LACROIX-GUEU et al., 2005). Contudo, esse movimento de vírus através dos canais de passagem de nutrientes pode ser afetado diretamente pela morfologia do vírus e diminuir sua capacidade de penetração. Nossos resultados sugerem que o biofilme dificulta a ação do bacteriófago ( $\varphi S P M-1)$ e diminui sua eficiência.

Mesmo que a difusão do bacteriófago ( $\varphi$ SPM-1) ocorra livremente através da matriz, a resistência do biofilme contra a fagoterapia pode ser resultado de diversos fatores: bloqueio do acesso do vírus aos sítios de ligação na membrana bacteriana, aprisionamento dos vírus e consequente diminuição de sua concentração livre no meio de cultura, redução na taxa metabólica das bactérias, entre outros fatores.

Kay e colaboradores testaram a eficácia de bacteriófagos contra biofilmes mistos de $E$. coli e $P$. aeruginosa. Seus resultados demonstram que os respectivos bacteriófagos foram eficazes contra os modelos planctônicos e de biofilmes mistos, mas quando o biofilme era formado em monocultura as bactérias não eram completamente eliminadas (KAY et al., 2010). Dessa forma, é importante esclarecer a interação entre bacteriófagos específicos e biofilmes bacterianos antes de sugerir a aplicação da fagoterapia contra biofilmes de $P$. aeruginosa.

\subsubsection{Resistência do biofilme de $P$. aeruginosa MR a terapia de sinergismo entre Aztreonam e Piperacilina/Tazobactam}

As discrepâncias observadas no valor da CIM do modelo planctônico e do modelo de biofilme corroboram os dados encontrados na bibliografia de que os canais de transporte de nutrientes presentes na matriz do biofilme dificultam a livre 
difusão de algumas classes de antibacterianos e podem reduzir a concentração real de antibióticos que atinge cada bactéria (Drenkard, 2003).

O sinergismo depende de concentrações específicas de dois antibacterianos diferentes serem aplicadas em conjunto contra uma bactéria. A presença da matriz pode influenciar o controle preciso das concentrações de antibacterianos e tornar a terapia de sinergismo ineficiente. Considerando que a difusão através do biofilme depende da classe de antibiótico utilizada, é necessário buscar combinações de antibióticos com similar capacidade de penetração através da matriz.

Contudo, é importante destacar que a resistência do biofilme aos antibacterianos é provavelmente causada por uma combinação de fatores além da presença da matriz. Mesmo antibióticos capazes de atingir as bactérias mais profundas de um biofilme, como as fluoroquinolonas, não são capazes de eliminar o biofilme de $P$. aeruginosa completamente. Dessa forma, a busca por alternativas terapêuticas deve ser uma prioridade na área de pesquisa médica.

\subsection{Uso de meio hipertônico MHB+FIA}

\subsubsection{Efeito do meio MHB+FIA em cepas de $P$. aeruginosa}

O efeito bactericida apresentado pelo meio hipertônico contra bactérias planctônicas indica que o $\mathrm{NaCl}$ atua além da redução de motilidade, podendo funcionar como um agente antibacteriano quando aplicado em elevadas concentrações.

A concentração de $\mathrm{NaCl} 7 \%$ foi capaz de inibir as 14 cepas testadas, tanto em modelo planctônico quanto em modelo de biofilme, enquanto a concentração de $\mathrm{NaCl}$ 14\% foi capaz de eliminar totalmente 10 das 14 cepas em modelo planctônico. Esses resultados sugerem um potencial terapêutico para o meio FIA.

Apesar de meio MHB+FIA ser capaz de inibir o crescimento planctônico do clone endêmico brasileiro MR de $P$. aeruginosa ST277 em concentrações de 3,5\%, os resultados com biofilmes já consolidados recomendam um mínimo de 7\% de $\mathrm{NaCl}$ para garantir que o biofilme não se propague.

O "MBEC Assay" não é capaz de detectar alterações na população bacteriana no biofilme, mas permite avaliar se as bactérias desse biofilme são capazes de se desprender da ponteira e agir como inoculo em novos meios de cultura. A utilização 
de meio $\mathrm{MHB}+\mathrm{FIA} \mathrm{7 \%} \mathrm{mostra-se} \mathrm{capaz} \mathrm{de} \mathrm{conter} \mathrm{a} \mathrm{expansão} \mathrm{do} \mathrm{biofilme} \mathrm{e} \mathrm{impedir}$ que ele se espalhe em novos meios de cultura. Uma concentração de $\mathrm{NaCl}$ a $14 \%$ seria capaz de inibir os biofilmes e eliminar as bactérias que retornem a forma planctônica.

Apesar do meio MHB+FIA perder sua capacidade bactericida quando aplicado em modelo de biofilme, o efeito bacteriostático é mantido. Este efeito é diferente do observado nas interações entre antibacterianos e biofilmes, situação em que a população bacteriana aumenta e o efeito inibitório do antibacteriano é perdido. É importante destacar que a terapia com meio FIA é recomendada apenas para uso tópico, possivelmente contendo a infecção enquanto outras terapias são aplicadas e/ou enquanto o sistema imune do paciente se recupera.

As cepas estudadas exibiram uma taxa de mortalidade muito menor do que a observada por Michon e colaboradores, pois após a formação do biofilme nenhuma concentração de $\mathrm{NaCl}$ utilizada apresentou atividade bactericida. Contudo, já foi demonstrado que a concentração inibitória mínima do $\mathrm{NaCl}$ tem correlação direta com a capacidade de aderência do biofilme (MICHON et al., 2014), sendo as linhagens fortemente aderentes mais resistentes ao $\mathrm{NaCl}$.

Fisiologicamente, a concentração plasmática de $\mathrm{NaCl}$ corresponde a 0,9\% (150 mM). Assim, na condição experimental favorável, uma possível formulação farmacêutica deveria conter aproximadamente 8 vezes a concentração plasmática de $\mathrm{NaCl}$, o qual restringiria a aplicação do FIA para uso tópico, o que incluiria a apresentação na forma de aerosol. De fato, esta concentração de $\mathrm{NaCl}$ já foi utilizada em paciente com fibrose cística infectados com $P$. aeruginosa, mostrando estabilidade clínica dos pacientes infectados com restabelecimento da função pulmonar (HAVASI et al., 2008), o que respalda a aplicabilidade terapêutica e/ou profilática para infecções do trato respiratório superior.

\subsubsection{Efeito do meio MHB+FIA na atividade de antibacterianos}

O meio $\mathrm{MHB}+\mathrm{FIA}$ é capaz de inibir o crescimento do biofilme, mas não eliminou completamente as bactérias. Combinações de antibacterianos com meio $\mathrm{MHB}+\mathrm{FIA}$ foram avaliadas com o objetivo de recuperar o efeito bactericida observado. 
A adição de Aztreonam ou Piperacilina/Tazobactam ao meio MHB+FIA não apresentou nenhuma melhora quando aplicados sobre o biofilme já formado. Mesmo a combinação de $512 \mu \mathrm{g} / \mathrm{mL}$ de antibacterianos em meio MHB + FIA com NaCl 14\%, concentrações mais elevadas utilizadas neste estudo, não foi capaz de eliminar os biofilmes formados em meio MHB.

\subsection{Efeito do meio MHB+FIA na formação do biofilme}

$O$ efeito bacteriostático do meio $\mathrm{MHB}+\mathrm{FIA}$ poderia ser utilizado de maneira profilática, antes da consolidação do biofilme de $P$. aeruginosa. A aplicação de MHB+FIA enquanto as bactérias ainda estão em sua forma planctônica pode reduzir a população inicial no biofilme bacteriano.

Apesar da aplicação de MHB + FIA em concentrações de $\mathrm{NaCl}$ a 3,5\% e 7\% não ser capaz de impedir completamente a formação de biofilmes, estes biofilmes foram menos resistentes contra o tratamento com antibacterianos. Como mostrado na tabela 8, biofilmes formados em meio FIA e transferidos para meios com antibiótico tiveram seu crescimento inibido em concentrações próximas as observadas no modelo planctônico.

Esses dados sugerem que uma possível alternativa terapêutica seria manter os pacientes recebendo antibióticos na concentração planctônica e, periodicamente, aplicar meio FIA sobre os possíveis sítios de infecção.

Este estudo indica que o meio MHB+FIA é capaz de influenciar a formação de biofilme e que trabalhos futuros deverão esclarecer os efeitos físico-químicos da concentração de $\mathrm{NaCl}$ sobre a célula bacteriana, elucidando o motivo do efeito bacteriostático observado e permitindo a escolha da melhor estratégia terapêutica para o tratamento de infecções causadas por Pseudomonas aeruginosa.

\subsection{Efeito do meio MHB+FIA na estrutura flagelar de $P$. aeruginosa}

Previamente, Havasi e colaboradores (2008), sugeriram que a atividade de uma alta concentração de sal inferia da inibição da síntese do flagelo, o que se traduziria em uma inibição do crescimento e possivelmente uma redução da população inicial formadora do biofilme. $O$ presente estudo, de fato, confirmo a atividade inibitória da FIA, incluindo, sobre cepas MRs produtoras de 
carbapenemases. Assim, para demonstrar a possível inibição do flagelo realizamos uma microscopia de transmissão eletrônica, utilizando como modelo a cepa de P. aeruginosa produtoras de GES-5. O cultivo em meio MHB com $7 \%$ de $\mathrm{NaCl}$ não inibiu a síntese do flagelo da cepa GES-5 de $P$. aeruginosa, como observado pela microscopia eletrônica. Contudo, é possível que estes flagelos não sejam funcionais e que a motilidade das bactérias esteja prejudicada, reduzindo a população de bactérias que inicia a formação do biofilme. Experimentos adicionais serão necessários para comprovar esta hipótese. 


\section{CONCLUSÕES}

1. O bacteriófago ( $\varphi S P M-1)$, eficaz na eliminação de $P$. aeruginosa em modelo planctônico, não foi capaz de eliminar as bactérias em modelo de biofilme.

2. A combinação dos antibióticos Aztreonam e Piperacilina/Tazobactam, eficaz na eliminação de $P$. aeruginosa em modelo planctônico, não foi capaz de eliminar as bactérias em modelo de biofilme, mesmo em elevadas concentrações de antibacterianos.

3. Meio de Força lônica Alta com $\mathrm{NaCl}$ a $7 \%$ teve efeito bacteriostático sobre as 14 cepas testadas, tanto em modelo de crescimento planctônico quanto em modelo de biofilme.

4. Meio de Força lônica Alta com $\mathrm{NaCl}$ a $14 \%$ foi capaz de eliminar 10 das 14 cepas testadas, apenas no modelo de crescimento planctônico.

5. Nenhuma das concentrações e combinações utilizadas foi capaz de eliminar completamente os biofilmes formados em meio MHB.

6. Biofilmes formados em meio MHB+FIA podem ter seu crescimento inibido por antibacterianos em concentrações semelhantes a CIM planctônica.

7. $\quad$ A FIA ( $\mathrm{NaCl} 7 \%)$ não inibe a síntese do flagelo de $P$. aeruginosa. 


\section{REFERÊNCIAS*}

ABEDON, S. T. Spatial vulnerability: bacterial arrangements, microcolonies and biofilms as responses to low rather than high phage densities. Viruses, v. 4, p. 663-687, 2012.

AKPAKA, P. E.; SWANSTON, W. H.; IHEMERE, H. N.; CORREA, A.; TORRES, J. A.; TAFUR, J. D.; MONTEALEGRE, M. C.; QUINN, J. P.; VILLEGAS, M. V. Emergence of KPC-producing Pseudomonas aeruginosa in Trinidad and Tobago. J. Clin. Microbiol., v. 47, p. 2670-2671, 2009.

ANDREATTI FILHO, R. L.; HIGGINS, J. P.; HIGGINS, S. E.; GAONA, G.; WOLFENDEN, A. D.; TELLEZ, G.; HARGIS, B. M. Ability of bacteriophages isolated from different sources to reduce Salmonella enterica serovar enteritidis in vitro and in vivo. Poult Sci., v. 86, n. 9, p.1904-1909, 2007.

BALSALOBRE, L. C.; DROPA, M.; LINCOPAN, N.; MAMIZUKA, E. M.; MATTÉ, G. R.; MATTÉ, M. H. Detection of metallo-beta-lactamases-encoding genes in environmental isolates of Aeromonas hydrophila and Aeromonas jandaei. Lett. Appl. Microbiol., v. 49, n. 1, p. 142-145, 2009.

BERGAN, T. Phage typing of Pseudomonas aeruginosa. Methods in Microbiology, v.10, p. 169-199, 1978.

BETTS, A.; VASSE, M.; KALTZ, O.; HOCHBERG, M. E. Back to the future: evolving bacteriophages to increase their effectiveness against the pathogen Pseudomonas aeruginosa PAO1. Evol. Appl., v. 6, n. 7, p. 1054-1063, 2013.

BOUCHER, H. W.; TALBOT, G. H., BRADLEY, J. S.; EDWARDS, J. E.; GILBERT, D.; RICE, L. B.; SCHELD, M.; SPELLBERG, B.; BARTLETT, J. Bad bugs, no drugs: no ESKAPE! An update from the Infectious Diseases Society of America. Clin. Infect. Dis., v. 48, n. 1, p.1-12, 2009.

BRITO, D. V. D.; OLIVEIRA, E. J.; DARINI, A. L. C.; ABDALLAH, V .O. S.; GONTIJO-FILHO, P. P. Nosocomial outbreaks due to Pseudomonas aeruginosa and Acinetobacter baumannii in a neonatal intensive care unit (NICU) of Uberlândia Federal University Hospital. Brazilian Journal of Microbiology, v. 34, p. 27-28, 2003.

BROOUN, A.; LIU, S.; LEWIS, K. A dose-response study of antibiotic resistance in Pseudomonas aeruginosa biofilms. Antimic. Agents Chemoter., v. 44, p. 640-646, 2000.

CARLTON, R. M. Phage therapy: past history and future prospects. Arch. Immunol. Ther. Exp. (Warsz), v. 47, n. 5, p. 267-274, 1999.

CERI, H.; OLSON, M. E.; STREMICK, C.; READ, R. R.; MORCK, D.; BURET, A. The Calgary Biofilm Device: New technology for rapid determination of antibiotic susceptibilities of bacterial biofilms. J. Clin. Microbiol., v. 37, n. 6, p. 1771-1776, 1999.

*De acordo com:

ASSOCIAÇÃO BRASILEIRA DE NORMAS TÉCNICAS. NBR 6023: informação e documentação: referências: elaboração. Rio de Janeiro, 2002. 
CHAPMAN, P. A.; ELLIN, M.; ASHTON, R.; SHAFIQUE, W. Comparison of culture, PCR and immunoassays for detecting Escherichia coli O157 following enrichment culture and immunomagnetic separation performed on naturally contaminated raw meat products. Int. J. Food Microbiol., v. 68, p. 11-20, 2001.

CHOI, J. Y.; PARK, Y. S.; CHO, C. H.; SEON, Y; SHIN, S. Y.; SONG, G; YONG, D; LEE, K; KIM, J. M. Synergic in-vitro activity of imipenem and sulbactam againt Acinetobacter baumannii. Clinical Microbioly and Infection, v. 10, p. 1089-1104, 2004.

CISLO, M.; DABROWSKI, M.; WEBER-DABROWSKA, B.; WOYTOÑ, A. Bacteriophage treatment of suppurative skin infections. Arch. Immunol. Ther. Exp., v. 35, n. 2, p. 175-183, 1987.

CLINICAL AND LABORATORY STANDARDS INSTITUTE (CLSI). Methods for dilution antimicrobial susceptibility tests for bacteria that growh aerobically. Approved Standard - Eight Edition, CLSI document M07-A8. Wayne, PA, 2009.

CLINICAL AND LABORATORY STANDARDS INSTITUTE (CLSI). Performand Standards for Antimicrobial Disk Susceptibility Test. Approved Standard - Tenth Edition, CLSI document M02A10. Wayne, PA: 2009.

CLINICAL AND LABORATORY STANDARDS INSTITUTE (CLSI). Performance Standards for antimicrobial susceptibility testing. Twentieh-three informational supplement. CLSI document M100-23. Wayne, PA: 2014.

COCHRANE, D. M. G.; BROWN, M. R. W.; ANWAR, H.; WELLER, P. H.; LAM, K.; COSTERTON, J. W. Antibody response to Pseudomonas aeruginosa surface protein antigens in rat model of chronic lung infection. J. Med. Microbiol., v. 27, n. 4, p. 255-261, 1988.

COOPER C. J.; DENYER, S. P.; MAILLARD, J. Y. Stability and purity of a bacteriophage cocktail preparation for nebulizer delivery. Lett. Appl. Microbiol., v. 25, n. 30, p. 803-813, 2013.

COSTERTON, J. W.; LEWANDOWSKI, Z.; CALDWELL, D. E.; KORBER, D. R.; LAPPIN-SCOTT, H. M. Microbial biofilms. Annu. Rev. Microbiol., v. 49, p. 711-745, 1995.

COSTERTON, J. W.; STEWART, P. S.; AND GREENBERG, E. P. Bacterial biofilms: a common cause of persistent infections. Science, v. 284, p. 1318-1322, 1999.

DA FONSECA, E. L.; VIEIRA, V. V.; CIPRIANO, R.; VICENTE, A. C. Emergence of blaGES-5 in clinical colistin-only-sensitive (COS) Pseudomonas aeruginosa strain in Brazil. J. Antimicrob. Chemother., v. 59, n. 3, p. 576-577, 2007.

DA SILVA FILHO, L. V.; TATENO, A. F.; VELLOSO, L. F.; LEVI, J. E.; FERNANDES, S.; BENTO, C. N.; RODRIGUES, J. C.; RAMOS, S. R. Identification of Pseudomonas aeruginosa, Burkholderia cepacia complex, and Stenotrophomonas maltophilia in respiratory samples from cystic fibrosis patients using multiplex PCR. Pediatr. Pulmonol., v. 37, p. 537-547, 2004.

DAVIES, D. G.; CHAKRABARTY, A. M.; GEESEY, G. G. Exopolysaccharide production in biofilms: substratum activation of alginate gene expression by Pseudomonas aeruginosa. Appl. Environ. Microbiol., v. 59, n. 4, p. 1181-1186, 1993. 
DEBARBIEUX, L.; LEDUC, D.; MAURA, D.; MORELLO, E.; CRISCUOLO, A.; GROSSI, O.; BALLOY, V.; TOUQUI, L. Bacteriophages can treat and prevent Pseudomonas aeruginosa lung infections. J. Infect. Dis., v. 201, n. 7, p. 1096-1104, 2010.

DE BEER, D.; SRINIVASAN, R.; STEWART, P. S. Direct measurement of chlorine penetration into biofilms during desinfection. Appl. Environ. Microbiol., v. 60, p. 4339-4344, 1994.

DONLAN, R. M. Biofilm elimination on intravascular catheter: important considerations for the infectious disease practitioner. Healthcare Epidemiology, v. 52, p. 1038-1045, 2011.

DRENKARD, E. Antimicrobial resistance of Pseudomonas aeruginosa. Microbes and Infection, v. 5, p. 1213-1219, 2003.

DROPA, M.; BALSALOBRE, L. C.; LINCOPAN, N.; MAMIZUKA, E. M.; CASSETTARI, V. C.; MATTÉ, G. R.; MATTÉ, M. H. Emergence of Klebsiella pneumoniae carrying the novel extended-spectrum beta-lactamase gene variants bla(SHV-40), bla(TEM-116) and the class 1 integron-associated bla(GES-7) in Brazil. Clin. Microbiol. Infect., v. 16, n. 6, p. 630-632, 2010.

DUBOIS, V. et al . Nosocomial outbreak due to a multiresistant strain of Pseudomonas aeruginosa P12: efficacy of cefepime-amikacin therapy and analysis of beta-lactam resistance. J. Clin. Microbiol., v. 39, p. 2072-8, 2001.

ESSOH, C.; BLOUIN, Y.; LOUKOU, G.; CABLANMIAN, A.; LATHRO, S.; KUTTER, E.;THIEN, H. V.; VERGNAUD, G.; POURCEL, C. The susceptibility of Pseudomonas aeruginosa strains from cystic fibrosis patients to bacteriophages. PLoS One., v. 8, n. 4, 2013.

EVANS, D. J.; ALLISON, D. G.; BROWN, M. R.; GILBERT, P. Susceptibility of Pseudomonas aeruginosa and Escherichia coli biofilms towards ciprofloxacin: effect of specific growth rate. J. Antimicrob. Chemother., v. 27, p. 177-184, 1991.

FIGUEIREDO, E. A. P.; RAMOS, H.; MACIEL, M. A. V.; VILAR, M. C. M.; LOUREIRO, N. G.; PEREIRA, R. G. Pseudomonas aeruginosa: frequência de resistência a múltiplos fármacos e resistência cruzada entre antimicrobianos no Recife/PE. Rev. Bras. Ter. Int., vol 19, n. 4, p. 421-427, 2007.

FILHO, L. S.; SANTOS, I. B.; ASSIS, A. M. L.; XAVIER, D. E. Determinação na produção de metallo$\beta$-lactamase em amostras de Pseudomonas aeruginosa isolado em João Pessoa, Paraíba. Jornal Brasileiro de Patologia e Medicina Laboratorial; v. 38, p. 79-84, 2002.

FIORENTIN, L.; VIEIRA, N. D.; BARIONI, W. J. R. Oral treatment with bacteriophages reduces the concentration of Salmonella Enteritidis PT4 in faecal contents of broilers. Avian Pathol., v. 34, n. 3, p. 258-263, 2005.

GALES, A. C.; MENEZES, L. C.; SILBERT, S.; SADER, H. S. Dissemination in distinct Brazilian regions of an epidemic carbapenem-resistant Pseudomonas aeruginosa producing SPM metallo- $\beta$ lactamase. Journal of Antimicrobial Chemotherapy, v. 52, p. 699-702, 2003.

GE C.; WEI, Z.; JIANG, Y.; SHEN, P.; YU, Y.; LI, L. Identification of KPC-2-producing Pseudomonas aeruginosa isolates in China. J. Antimicrob. Chemother., v. 66, p. 1184-1186, 2011. 
GIAMARELLOS-BOURBOULIS, E. J.; GRECKA P; GIAMARELLOU, H. Comparative in vitro interactions of ceftazidime, meropenem, and imipenem with amikacina on multiresistant Pseudomonas aeruginosa. Diagn. Microbiol. Infect. Dis., v. 29, n. 2, p.81-86, 1997.

GONÇALVES, D. C. P. S; LIMA, A. B. M.; LEÃO, L. S. N. O.; FILHO, J. R. C.; PIMENTA, F. C.; VIEIRA, J. D. G. Detecção de metalo-beta-lactamase em Pseudomonas aeruginosa isoladas de pacientes hospitalizados em Goiânia, Estado de Goiás. Rev. Soc. Bras. de Med. Trop., v. 42, n. 4, p. 411-414, 2009.

GRÄF, T.; FUENTEFRIA, D. B.; CORÇÃO, G. Ocorrência de cepas de Pseudomonas aeruginosa multirresistentes produtoras de metalo-beta-lactamase blaSPM-1 em amostras clínicas. Rev. Soc. Bras. Med. Trop., v. 41, n. 3, p. 306-308, 2008.

HALL M. J; MIDDLETON R. F.; WESTMACOTT D. The fractional inhibitory concentration (FIC) index as a measure of synergy. J. Antimicrob. Chemother., v. 11, n. 5, p. 427-433, 1983.

HARPER, D. R.; ENRIGHT, M. C. Bacteriophages for the treatment of Pseudomonas aeruginosa infections. J. Appl. Microbiol., v. 111, n. 1, p.1-7, 2011.

HAVASI, V; HURST, C. O.; BRILES, T. C.; YANG, F.; BAINS, D. G.; HASSETT, D. J.; SORSCHER, E. Inhibitory effects of hypertonic saline on P. aeruginosa motility. Journal of Cystic Fibrosis., v. 7, p. 267-269, 2008.

HENRY, M.; LAVIGNE, R.; DEBARBIEUX, L. Predicting in vivo efficacy of therapeutic bacteriophages used to treat pulmonary infections. Antimicrob. Agents Chemother., v. 57, n. 12, p. 5961-5968, 2013.

HUANG, C. T.; YU, F. P.; MCFETERS, G. A.; STEWART, P. S. Nonuniform spatial patterns of respiratory activity within biofilms during disinfection. Appl. Environ. Microbiol., vol 61, 2252-2256, 1995.

JÁCOME, P. R. L. A.; ALVES, L. R.; CABRAL, A. B.; LOPES, A. C. S.; MACIEL, M. A. V. First reporto f KPC-producing Pseudomonas aeruginosa in Brazil. Antimicrob. Agents Chemother., v. 56, n. 9, p. 4990, 2012.

JENSEN, E. C.; SCHRADER, H. S.; RIELAND, B.; THOMPSON, T. L.; LEE, K. W.; NICKERSON, K. W.; KOKJOHN, T. A. Prevalence of Broad-Host-Range Lytic Bacteriophages of Sphaerotilus natans, Escherichia coli, and Pseudomonas aeruginosa. Appl. Envir. Microbiol., v. 64, p. 575-580, 1998.

KARLOWSKY, J. A.; WEAVER, M. K.; THORNSBERRY, C; DOWZICKY, M. J.; JONES, M. E.; SAHM, D. F. Comparison of Four Antimicrobial Susceptibility Testing Methods To Determine the In Vitro Activities of Piperacillin and Piperacillin-Tazobactam against Clinical Isolates of Enterobacteriaceae and Pseudomonas aeruginosa. Journal of Clinical Microbiology, v. 41, p. 3393343, 2003.

KAY, M. K.; THOMAS C.; ERWIN, R. J.; MCLEAN, C.; ARON, G. M. Bacteriophage Ecology in Escherichia coli and Pseudomonas aeruginosa mixed-biofilm communities. Appl. Environ. Microbiol., v. 77, n. 3, p. 821, 2011. 
KHOURY, A. E.; LAM, K.; ELLIS, B. D.; COSTERTON, J. W. Prevention and control of bacterial infections associated with medical devices. Am. Soc. of Artif. Intern. Organs, v. 38, p. 174-178, 1992.

KOBAYASHI, C. C. B. A.; SADOYAMA, G.; VIEIRA, J. D. G. Determinação da resistência antimicrobiana associada em isolados clínicos de Staphylococcus aureus e Pseudomonas aeruginosa em um hospital público de Goiânia, Estado de Goiás. Rev. Soc. Bras. Med. Trop., v. 42, n. 4, p. 404410, 2009.

KUMARI, S.; HARJAI, K.; CHHIBBER, S. Bacteriophage Treatment of Burn Wound Infection Caused by Pseudomonas aeruginosa PAO in BALB/c Mice. Am. J. Biomed. Sci., v. 1, n. 4, p. 385-394, 2009.

LACROIX-GUEU, P.; BRIANDET, R.; LÉVÊQUE-FORT, S.; MARIE-NOËLLE, B. F.; MARIE-PIERRE, F. A. In situ measurements of viral particles diffusion inside mucoid biofilms. C. R. Biologies, v. 328, p. 1065-1072, 2005.

LAMBE Jr., D. W.; FERGUSON, K. P.; MAYBERRY-CARSON, K. J.; TOBER-MEYER, B.; COSTERTON, J. W. Foreign-body-associated experimental osteomyelitis induced with Bacterioides fragilis and Staphylococcus epidermidis in rabbits. Clin. Orthop., v. 266, p. 285-294, 1991.

LEVINE, A. J. Viruses. Scientific American Library, p. 25-45, 1992.

LI, C.; ADLER, J. Escherichia coli shows two types of behavioral responses to osmotic upshift. J. Bacteriol., v. 175, p. 2564-2567, 1993.

LINCOPAN, N.; MACCULLOCK, J. A.; CASSETTARI, V. C.; GALES, A. C.; MAMIZUKA, E. M. First isolation of metallo-beta-lactamase-producing multiresistant Klebsiella pneumoniae from a patient in Brazil. Journal of Clinical Microbiology, v. 43, n. 1, p. 516-519, 2005.

LINCOPAN N, LEIS R, VIANELLO M. A, DE ARAÚJO M. R, RUIZ A. S, MAMIZUKA E. M. Enterobacteria producing extended-spectrum $\beta$-lactamases and IMP-1 metallo- $\beta$-lactamases isolated from Brazilian hospitals. J. Med. Microbiol., v. 55, p. 1611-1613, 2006.

LORCH, A. Bacteriophages: an alternative to antibiotics? Biotechnology and Development Monitor, v. 39, p. 14-17, 1999.

LOUREIRO, M. M.; MORAES, B. A.; QUADRA, M. R. R.; PINHEIRO, G. S.; ASENSI, M. D. Study of multi-drug resistant microorganisms isolated from blood cultures of hospitalized newborns in Rio de Janeiro city, Brazil. Braz. Journ. of Microb., v. 33, p. 73-78, 2002.

LYNCH, S. V.; WILNER-KRONESH, J. P. Novel strategies to combat bacterial virulence. Curr. Opin. Crit., v. 14, n. 5, p. 593-599, 2008.

MAGIORAKUS, A. P.; SRINIVASAN, A.; CAREY, R. B.; CARMELI, Y.; FALAGAS, M. E.; GISKE, C. G.; HARBARTH, S.; HINDLER, J. F.; KAHLMETER, G.; OLSSON-LILJEQUIST, B.; PATERSON, D. L.; RICE, L. B.; STELLING, J.; STRUELENS, M. J.; VATOPOULOS, A.; WEBER, J. T.; MONNET, D.

L. Multidrug-resistant, extensively drug-resistant and pandrug-resistant bacteria: an international expert proposal for interim standard definitions for acquired resistance. Clin. Microbiol. Infect., v. 18, n. 3, p. 268-281, 2012. 
MARRIE, T. J.; NELLIGAN, J.; COSTERTON, J. W. A scanning and transmission electron microscopic study of an infected endocardial pacemaker lead. Circulation, v. 66, p. 1339, 1982.

MCVAY, C. S.; VELÁSQUEZ, M.; FRALICK, J. A. Phage therapy of Pseudomonas aeruginosa infection in a mouse burn wound model. Antimicrob. Agents Chemother., v. 51, n. 6, p. 1934-1938, 2007.

MENDES, R. E.; CASTANHEIRA, M.; PIGNATARI, A. C. C,; GALES, A. C. Metallo-B-lactamases. Jornal Brasileiro de Patologia e Medicina Laboratorial, v. 42, p. 103-113, 2006.

MERABISHVILI, M.; PIRNAY, J. P.; VERBEKEN, G.; CHANISHVILI, N.; TEDIASHVILI, M.; LASHKHI, N.; GLONTI, T.; KRYLOV, V.; MAST, J.; VAN PARYS, L.; LAVIGNE, R.; VOLCKAERT, G.; MATTHEUS, W.; VERWEEN, G.; DE CORTE, P.; ROSE, T.; JENNES, S.; ZIZI, M.; DE VOS, D.; VANEECHOUTTE, M. Quality-controlled small-scale production of a well-defined bacteriophage cocktail for use in human clinical trials. PLoS One, v. 4, n. 3, 2009.

MICHON, A. L.; JUMAS-BILAK, E.; CHIRON, R.; LAMY, B.; MARCHANDIN, H. Advances toward the Elucidation of Hypertonic Saline Effects on Pseudomonas aeruginosa from Cystic Fibrosis Patients. PLoS One, v. 9, n. 2, 2014.

MOURA, J. P.; GIR, E. Conhecimento dos profissionais de enfermagem referente à resistência bacteriana a múltiplas drogas. Acta Paul. Enferm., v. 20, n. 3, p. 351-356, 2007.

NATECHE, F.; MARTIN, A.; BARAKA, S.; PALOMINO, J. C.; KHALED, S.; PORTAELS, F. Application of the resazurin microtitre assay for detection of multidrug resistance in Mycobacterium tuberculosis in Algiers. J. Med. Microbiol., v. 55, p. 857-860, 2006.

NEVES, P. R. Alterações da permeabilidade e expressão de bombas de efluxo em isolados clínicos de Pseudomonas aeruginosa resistente ao imipenem. 2010. 100p. Tese (Doutorado em Farmácia) Faculdade de Ciências Farmacêuticas, Universidade de São Paulo, São Paulo, 2010.

NEVES, P. R.; MAMIZUKA, E. M.; LEVY, C. E.; LINCOPAN, N. Pseudomonas aeruginosa multirresistente: um problema endêmico no Brasil. J. Bras. Patol. Med. Lab., v. 47, n.4, p. 409-420, 2011.

NEVES, P. R.; CERDEIRA, L. T.; MITNE-NETO, M.; OLIVEIRA, T. G. M.; McCULLOCH, J. A.; SAMPAIO, J. L. M.; MAMIZUKA, E. M.; LEVY, C. E.; SATO, M. I. Z.; LINCOPAN, N. Complete Genome Sequence of an F8-Like Lytic Myovirus (SPM-1) That Infects Metallo--Lactamase-Producing Pseudomonas aeruginosa. Genome Announc., v. 2, n. 2, 2014.

NICKEL, J. C.; RUSESKA, I.; WRIGHT, J. B.; COSTERTON, J. W. Tobramycin resistance of Pseudomonas aeruginosa cells growing as a biofilm on urinary catheter material. Antimic. Agents Chemother., v. 27, p. 619-624, 1985.

NISHIO, H.; KOMATSU, M.; SHIBATA, N.; SHIMAKAWA, K.; SUEYOSHI, N.; URA, T.; SATOH, K.; TOYOKAWA, M.; NAKAMURA, T.; WADA, Y.; ORITA, T.; KOFUKU, T.; YAMASAKI, K.; SAKAMOTO, M.; KINOSHITA, S.; AIHARA, M.; ARAKAWA, Y. Metallo-beta-lactamase-producing gram-negative bacilli: laboratory-based surveillance in cooperation with 13 clinical laboratories in the Kinki region of Japan. J. Clin. Microbiol., v. 42, n. 11, p. 5256-5263, 2004. 
OLIVEIRA, A.; SILLANKORVA, S.; QUINTA, R.; HENRIQUES, A.; SERENO, R.; AZEREDO, J. Isolation and characterization of bacteriophages for avian pathogenic E. coli strains. Journal of Applied Microbiology., v. 106, n. 6, p. 1919-1927, 2009.

PAISANO, A. F.; SPIRA, B.; CAI, S.; BOMBANA, A. C. In vitro antimicrobial effect of bacteriophages on human dentin infected with Enterococcus faecalis ATCC 29212. Oral Microbiol. Immunol., v. 19, n. 5, p. 327-330, 2004.

PANAGIOTAKOPOULOU, A.; DAIKOS, G. L. Comparative in vitro killing of carbapenems and aztreonam against Klebsiella pneumoniae producing VIM-1 metallo-ß-lactamase. Journal of Antimicrobial Agents, v. 29, p. 356-365, 2007.

PASTERÁN, F.; FOCCONE, D.; GOMEZ, S.; DE BUNDER, S.; SPINELLI, F.; RAPOPORT, M.; PETRONI, A.; GALAS, M.; CORSO, A. Detection of an international multiresistant clone belonging to sequence type 654 involved in the dissemination of KPC-producing Pseudomonas aeruginosa in Argentina. J. Antimicrob. Chemother., v. 67, n. 5, p. 1291-1293, 2012.

PATERSON, D. L; LIPMAN, J. Returning to the pre-antibiotic era in the critically ill: the XDR problem. Crit. Care Med., v. 35, n. 7, p. 1789-1791, 2007.

PELLEGRINO, F. L.; NETTO-DOS SANTOS, K. R.; RILEY, L. W.; MOREIRA, B. M. BlaGES carrying Pseudomonas aeruginosa isolates from a public hospital in Rio de Janeiro, Brazil. Braz. J. Infect. Dis., v. 10, n. 4, p. 251-253, 2006.

PICÃO, R. C.; ANDRADE, S. A.; NICOLETTI, A. G.; CAMOANA, E. H.; MOARES, G. C.; MENDES, R. E.; GALES, A. C. Metallo-beta-lactamase detection: comparative evaluation of double-disk synergy versus combined disk tests for IMP-, GIM-, SIM-, SPM-, or VIM-producing isolates. Journal of Clinical Microbiology, v. 46, n. 6, p. 2028-2037, 2008.

PICÃO, R. C.; SANTOS, A. F.; NICOLETTI, A. G.; FURTADO, G. H.; GALES, A. C. Detection of GES5-producing Klebsiella pneumoniae in Brazil. J. Antimicrob. Chemother., v. 65, n. 4, p. 796-797, 2010.

PIRES, M. C. S.; FROTA, K. S.; MARTINS Jr, P. O.; CORREIA, A. F.; CORTEZ-ESCALANTE, J. J.; SILVEIRA, C. A. Prevalência e suscetibilidades bacterianas das infecções comunitárias do trato urinário, em Hospitl Universitário de Brasília, no período de 2001 a 2005. Rev. Soc. Bras. Med. Trop., v. 40, n. 6, p. 643-647, 2007.

POIREL, L.; COLLET, L.; NORDMANN, P. Carbapenem-Hydrolyzing Metallo-ß-Lactamase from a Nosocomial Isolate of Pseudomonas aeruginosa in France. Emerg. Infect. Dis., v. 6, n. 1, p. 84-85, 2000.

POIREL, L.; NORDMANN, P.; LAGRUTTA, E.; CLEARY, T.; MUNOZ-PRICE, L. S. Emergence of KPC-producing Pseudomonas aeruginosa in the United States. Antimicrob. Agents Chemother., v. 54, p. 3072, 2010.

POLLACK, M. Pseudomonas aeruginosa. In: MANDELL, G. L.; BENNETT, J. E.; DOLIN, R. (Ed.). Mandell, Douglas and Bennett's principles and practice of infectious diseases. Philadelphia, PA: Churchill Livingstone, 2000. p. 2310-2335. 
POLOTTO, M.; CASELLA, T.; OLIVEIRA, M. G. L.; RÚBIO, F. G.; NOGUEIRA, M. L.; DE ALMEIDA, M. T.; NOGUEIRA, M. C. Detection of P. aeruginosa harboring bla CTX-M-2, bla GES-1 and bla GES5, bla IMP-1 and bla SPM-1 causing infections in Brazilian tertiary-care hospital. BMC Infect. Dis., v. 3, n. 12, p.176, 2012.

PULCINELLI, R. S. R.; SAUCEDO, E. M.; PEREIRA, R.; PILONETTO, M.; AQUINO A. R. C.; SANTOS, R. C. V. Detecção de metalo-beta-lactamases em amostras de Pseudomonas aeruginosa isoladas em Porto Alegre, Rio Grande do Sul. R. B. A. C., v. 41, n. 3, p. 197-199, 2009.

QUEENAN, A. M.; BUSH, K. Carbapenemases: the Versatile $\beta$-Lactamases. Clinical Microbiology Review, v. 3, p. 440-458, 2007.

RIBEIRO, V. B.; FALCI, D. R.; ROZALES, F. P.; BARTH, A. L.; ZAVASCKI, A. P. Carbapenemresistant GES-5-producing Klebsiella pneumoniae in Southern Brazil. Braz. J. Infect. Dis., v. 18, n. 2, p. 231-232, 2014.

SADER, H. S.; GALES, A. C.; PFALLER, M. A.; MENDES, R. E.; ZOCCOLI, C.; BARTH, A.; JONES, R. N. Pathogen frequency and resistance patterns in Brazilian hospitals: summary of results from three years of the SENTRY Antimicrobial Surveillance Program. Braz. J. Infect. Dis., v. 5, n. 4, p. 200-214, 2001.

SADER, H. S.; REIS, A. O.; SILBERT, S.; GALES, A. C. IMPs, VIMs and SPMs: the diversity of metallo-beta-lactamases produced by carbapenem-resistant Pseudomonas aeruginosa in a Brazilian hospital. Clin. Microbiol. Infect., v. 11, n. 1, p. 73-76, 2005.

SANTOS FILHO, L.; SANTOS, I. B.; ASSIS, A. M. L.; XAVIER, D. E. Determinação da Produção de metalo beta-lactamases em amostras de Pseudomonas aeruginosa isoladas em João Pessoa, Paraíba. Revista Brasileira de Patologia, v. 38, n. 01, p. 79-84, 2002.

SHI, W.; LI, C.; LOUISE, C. J.; ADLER J.; Mechanism of adverse conditions causing lack of flagella in Escherichia coli. J. Bacteriol., v. 175, n. 8, p. 2236-2240, 1993.

SILVA, J. L.; HIRATA, R. D. C.; HIRATA, M. H. Bacteriophage: laboratorial diagnosis and phage therapy. Braz. J. Microbiol., v. 40, n. 3, p. 547-549, 2009.

SILVA, F. M.; CARMO, M. S.; SILBERT, S.; GALES, A. C. SPM-1-producing Pseudomonas aeruginosa: analysis of the ancestor relationship using multilocus sequence typing, pulsed-field gel electrophoresis, and automated ribotyping. Microb. Drug Resist., v. 17, n. 2, p. 215-220, 2011.

SIQUEIRA, R. S.; DODD, C. E. R.; REES, C. E. D. Phage amplification assay as rapid method for Salmonella detection. Braz. J. Microbiol., v. 34, p. 118-120, 2003.

SMITH, H. W.; HUGGINS, M. B. Successful treatment of experimental Escherichia coli infections in mice using phage: its general superiority over antibiotics. J. Gen. Microb., v. 128, n. 2, p. 307-318, 1982.

SOOTHILL, J. S. Treatment of experimental infections of mice with bacteriophages. J. Med. Microbiol., v. 37, p. 258-261, 1992. 
SOOTHILL, J. Use of bacteriophages in the treatment of Pseudomonas aeruginosa infections. Expert Rev. Anti. Infect. Ther., v. 11, n. 9, p. 909-915, 2013.

SOUSA, M. A.; MENDES, E. N.; APOLÔNIO, A. C.; FARIAS, L. D. E. M.; MAGALHÃES, P. P. Bacteriocin production by Shigella sonnei isolated from faeces of children with acute diarrhoea. APMIS, v. 118, n. 2, p. 125-135, 2010.

STERNBERG, C.; CHRISTENSEN, B. B.; JOHANSEN, T.; TOFTGAARD-NIELSEN, A.; ANDERSEN, J. B.; GIVSKOV, M.; MOLIN, S. Distribution of bacterial growth activity in flow-chamber biofilms. Appl. Environ. Microbiol., v. 65, p. 4108-4117, 1999.

STONE, G.; WOOD, P.; DIXON, L.; KEYHAN, M.; MATIN, A. Tetracycline rapidly reaches all the constituent cells of uropathogenic Escherichia coli biofilms. Antimic. Agents Chemother., v. 46, p. 2458-2461, 2002.

SUCI, P. A.; MITTELMAN, M. W.; YU, F. P.; GEESEY, G. G. Investigation of ciprofloxacin penetration into Pseudomonas aeruginosa biofilms. Antimic. Agents Chemother., v. 38, p. 2125-2133, 1994.

SUTHERLAND, I. W.; Polysaccharide lyases. FEMS Microbiol. Rev., v. 16, p. 323-347, 1995.

SUTHERLAND, I. W. Polysaccharases for microbial polysaccharides. Carbohydr. Polym., v. 38, p. 319-328, 1999.

SUTHERLAND, I. W.; HUGHES, K. A.; SKILLMAN, L. C.; TAIT, K. The interaction of phage and biofilms. FEMS Microbiology Letters, v. 232, p. 1-6, 2004.

TANAKA, G.; SHIGETA, M.; KOMATSUZAWA, H.; SUGAI, I.; SUGINAKA, H.; USUI, T. Effect of the growth rate of Pseudomonas aeruginosa biofilms on the susceptibility to antimicrobial agents: betalactams and fluoroquinolonas. Chemoterapy, v. 45, p. 28-36, 1999.

TRAVIS, J. Viruses that slay bacteria draw new interest. Science News, v. 157, p. 358-360, 2000.

TRIPODI, M. F.; DURANTE-MANGONI, E.; FORTUNATO, R.; UTILI, R.; ZARRILLI, R. Comparation activities of Colistin, Rifampicina, Imipenem and Sulbactam/ampicillin alone or in combination agaist epidemic multidrug-resistant Acinetobacter baumannii isolates producing OXA-58 carbapenemases. Journal of Antimicrobial Agents, v. 30, p. 537-540, 2007.

TSAKRIS, A . et al . Outbreak of infections caused by Pseudomonas aeruginosa producing VIM-1 carbapenemase in Greece. J. Clin. Microbiol., v. 38, p. 1290-1292, 2000.

TURANO, H.G. Alternativas terapêuticas para o tratamento de infecções para o tratamento de infecções por Pseudomonas aeruginosa multirresistentes endêmicas no Brasil. $85 \mathrm{p}$. Dissertação (Mestrado em Microbiologia) - Instituto de Ciências Biomédicas, Universidade de São Paulo, São Paulo, 2012.

VAN VOORTHUIZEN, E. M.; ASHBOULT, N. J.; SCHÄFER, A. I. Role of hydrophobic and electrostatic interactions for initial enteric virus retention by MF membranes. J. Membr. Sci., v. 194, p. 69-79, 2001. 
VRANY, J. D.; STEWART, P. S.; SUCI, P. A. Comparison of recalcitrance to ciprofloxacin and levofloxacin exhibited by Pseudomonas aeruginosa biofilms displaying rapid-transport characteristics. Antimic. Agents Chemother., v. 41, p. 1352-1358, 1997

XU, K. D.; STEWART, P. S.; XIA, F.; HUANG, C. T.; MCFETERS, G. A. Spatial physiological heterogeneity in Pseudomonas aeruginosa biofilm is determined by oxygen avaibility. Appl. Environ. Microbiol., v. 64, p. 4035-4039, 1998.

WALSH, T. R.; TOLEMAN, M. A.; POIREL, L.; NORDMANN, P. Metallo-B-lactamases: the Quiet before the Storm?. Clinical Microbiology Reviews, v. 2, p. 306-325, 2005.

WALSH, T. R. Clinically significant carbapenemases: an update. Current Opinion in Infectious Diseases, v. 21, n. 4, p. 367-371, 2008.

WALTERS III, M. C.; ROE, F.; BUGNICOURT, A.; FRANKLIN, M. J.; STEWART, P. S. Contributions of antibiotic penetration, oxygen limitation, and low metabolic activity to tolerance of Pseudomonas aeruginosa biofilms to ciprofloxacin and tobramycin. Antimic. Agents Chemother., v. 47, p. 317-323, 2003.

WANG, J.; HU, B.; XU, M.; YAN, Q.; LIU, S.; ZHU, X.; SUN, Z.; REED, E.; DING, L.; GONG, J.; LI, Q. Q.; HU, J. Use of bacteriophage in the treatment of experimental animal bacteremia from imipenemresistant Pseudomonas aeruginosa. Int. J. Mol. Med., v. 17, n. 2, p. 309-317, 2006.

WARD, K. H.; OLSON M. E.; LAM, K.; COSTERTON, J. W. Mechanism of persistent infection associated with peritoneal implants. J. Med. Microbiol., v. 36, p. 406, 1992.

WENTLAND, E. J.; STEWART, P. S.; HUANG, C. T.; MCFETERS, G. A. Spatial variations in growth rate within Klebsiella pneumonia colonies and biofilm. Biotechnol. Prog., v. 12, p. 316-321, 1996.

WOLTER, D. J.; KURPIEL, P. M.; WOODFORM, N.; PALEPOU, M. F. I.; GOERING, R. V.; HANSON, N. D. Phenotypic and enzymatic comparative analysis of the novel KPC variant KPC-5 and its evolutionary variants, KPC-2 and KPC-4. Antimicrob. Agents Chemother., v. 53, p. 557-562, 2009.

ZAVASCKI, A. P.; BARTH, A. L.; GONÇALVES, A. L. S.; MORO, A. L. D.; FERNANDES, J. F.; MARTINS, A. F.; RAMOS, F.; GOLDANI, L. Z. The influence of metallo-B-lactamase production on mortality in nosocomial Pseudomonas aeruginosa infections. J. Antimicrob. Chemother., v. 58, p. 387-392, 2006.

ZHANE, G. G.; MAYER, M.; LAING, N.; ADAM, H. J. Mutant Prevention Concentrations of Levofloxacin Alone and in Combination with Azithromycin, Ceftazidime, Colistin (Polymyxin E), Meropenem, Piperacillin-Tazobactam, and Trobramycin against Pseudomonas aeruginosa. Antimicrobial Agents and Chemotherapy, v. 50, p. 2228-2230, 2006.

ZHANG, Y.; HUNT, H. K.; HU, Z. Application of bacteriophages to selectively remove Pseudomonas aeruginosa in water and wastewater filtration systems. Water Res., v. 47, n. 13, p. 4507-4518, 2013. 